\title{
Deciphering the Fall and Rise in the Net Capital Share: Accumulation or Scarcity?
}

\begin{abstract}
In the postwar era, developed economies have experienced two substantial trends in the net capital share of aggregate income: a rise during the last several decades, which is well known, and a fall of comparable magnitude that continued until the 1970s, which is less well known. Overall, the net capital share has increased since 1948, but once disaggregated this increase turns out to come entirely from the housing sector: the contribution to net capital income from all other sectors has been zero or slightly negative, as the fall and rise have offset each other. Several influential accounts of the recent rise emphasize the role of increased capital accumulation, but this view is at odds with theory and evidence: it requires empirically improbable elasticities of substitution, and it presumes a correlation between the capital-income ratio and capital share that is not visible in the data. A more limited narrative that stresses scarcity and the increased cost of housing better fits the data. These results are clarified using a new, multisector model of factor shares.
\end{abstract}

ow is aggregate income split between labor and capital? Ever since David Ricardo (1821) pronounced it the "principal problem of Political Economy," this question of distribution has both puzzled and inspired economists. Views differ. In one popular interpretation, the division between labor and capital remains remarkably stable over time: John Maynard Keynes (1939) called this stability "one of the most surprising, yet best-established, facts in the whole range of economic statistics" (p. 48), and Nicholas Kaldor (1957) immortalized it as one of the stylized facts of economic growth. In contrast, another tradition has emphasized variation in income shares: Robert Solow (1958) was famously skeptical, disputing the labor share's status as "one of the great constants of nature." Recently, Solow's view has experienced a resurgence, with the labor share apparently trending downward. Michael Elsby, Bart Hobijn, and Ayşegül Şahin (2013) carefully document this decline for the United States, and Loukas Karabarbounis 
and Brent Neiman (2014a) describe a broad, worldwide retreat of labor income in favor of capital.

Some influential recent narratives of this shift adopt what I call the accumulation view: capital's share has risen, and will continue to rise, because of capital accumulation. According to Thomas Piketty (2014) and Piketty and Gabriel Zucman (2014), several forces are driving up aggregate savings relative to income, and the resulting growth in the ratio of the capital stock to income has led to a rise in capital's share. Alternatively, Karabarbounis and Neiman (2014a) stress the role of falling prices for investment goods; in their account, lower prices lead to more aggregate capital investment and ultimately more capital income. Although these two narratives specify different initial shocks, the subsequent channel is common to both: accumulation of capital through investment leading to growth in capital income, because the rising quantity of capital is not fully offset by a fall in the returns per unit of capital.

This paper argues against the accumulation view on both empirical and theoretical grounds. Empirically, it reveals that the long-term increase in capital's net share of income in large developed countries has consisted entirely of housing. Outside of housing, capital's rise in recent decades has merely reversed a substantial earlier fall, and in neither direction has there been a parallel movement in the value of capital -all facts that are difficult to reconcile with the accumulation view.

From a more theoretical perspective, the accumulation view is only successful when the elasticity of substitution between labor and capital is sufficiently high. Clarifying the distinction between elasticities gross and net of depreciation, this paper argues that the elasticity required is much higher than the existing literature (particularly Piketty [2014]) suggests.

Moving beyond the canonical one-sector model to a multisector model that explicitly acknowledges some important dimensions of capital heterogeneity-for instance, the distinction between housing and nonhousing and the distinction between equipment and structures-I continue to find little support for either version of the accumulation view. Instead, a more viable, if incomplete, explanation of recent trends is that residential investment has become more expensive and land scarcer. Although this has lowered the quantity of housing, there has been a more than offsetting rise in net rents per unit of housing, pushing up the contribution of housing to capital's net share of income. In short, the data and theory support a scarcity view: the net capital share is rising in part because some forms of capital are becoming relatively more scarce, not more abundant. 
I begin the paper with a look at the evidence on factor income shares for large developed economies over the postwar period 1948-2010. Several conceptual issues are crucial, especially the distinction between gross and net shares. Although both gross and net concepts are worthwhile when interpreted properly, I argue that the net viewpoint-much less common among recent entries in the literature-applies more directly to the discussion of distribution and inequality, because it reflects the resources that individuals are ultimately able to consume. I also restrict attention to the private sector, and in light of the severe measurement difficulties for proprietor's income identified by Elsby, Hobijn, and Şahin (2013), among other authors, I apply the net shares from the corporate sector to the nonhousing sector as a whole.

This measurement reveals a striking discrepancy in the long-term behavior of gross and net shares, echoing the claims of Benjamin Bridgman (2014). It shows that the net capital share generally fell from the beginning of the sample through the mid-1970s, at which point the trends reversed. In the long run, there is a moderate increase in the aggregate net capital share, but this owes entirely to the housing sector. Indeed, housing's average portion of the aggregate net capital share rose from roughly 3 percent to 9 percent over the sample period, even as the private sector fell from 23 to 20 percent. This essential role of housing is notably absent from previous discussions of the factor distribution of income and represents an important new contribution of this paper. It parallels a large (though less dominant) role for rising housing wealth in the aggregate wealth-income ratio, which has been documented by Piketty and Zucman (2014), Bonnet and others (2014), and other researchers.

Although these two trends are sometimes conflated, their alignment is not preordained: in fact, in section IV I find that a shock to savings should push them in opposite directions. Outside of housing, there is a pronounced U-shape in the net capital share, with a steep fall in the 1970s and a more recent recovery. At shorter horizons, there is also a strong cyclical element, as long acknowledged by observers ranging from Wesley Mitchell (1913) to Julio Rotemberg and Michael Woodford (1999). To gauge whether the long-term fall and rise is consistent with the accumulation view, I contrast it with the time series for the capital-income ratio, finding that there is little similarity between the two. Using U.S. data on the value of the three major components of nonhousing capital-equipment, structures, and landI perform a simple decomposition of the net capital share into returns on these components, plus a residual that can be interpreted as representing firm markups over cost. Markups are responsible for most of the change 
in shares, in both directions; in particular, accumulation of equipment or structures cannot explain the recent rise.

With these facts in mind, I next ask whether the accumulation view is viable theoretically. First, I look at the canonical single-sector model with a production function $F(K, N)$ that combines capital and labor. Here, for both the Piketty (2014) and Karabarbounis and Neiman (2014a) narratives, the key parameter is the elasticity of substitution for $F$. One important oversight in past discussions, however, has been the distinction between gross and net $F$ : the elasticity for gross production is always higher than the elasticity for net.

The Piketty (2014) hypothesis-accumulation through aggregate savings driving up the net capital share-is only viable if the net elasticity of substitution is greater than 1, which I argue is out of line with most existing evidence. The related conjecture of rising $r-g$ requires even more unlikely levels of substitutability. By contrast, the Karabarbounis and Neiman (2014a) hypothesis only calls for a gross elasticity above 1, which I argue is more plausible although still unlikely.

Given the limitations of the single-sector model, to better confront the data and formulate an alternative to the accumulation view I build a multisector model that incorporates key distinctions between sectors (housing and nonhousing) and types of capital (equipment, structures, and land). When calibrated to match the structure of the U.S. economy, this model continues to contradict Piketty (2014). For any choice of lowerlevel elasticities near the range suggested by the literature, an increase in savings results in a lower net capital share. By contrast, the mechanism in Karabarbounis and Neiman (2014a) remains theoretically viable when labor and equipment are close substitutes; however, it works by increasing the value of equipment relative to total income, which is not consistent with the time-series evidence.

The multisector model offers better support for the scarcity view. If, as most evidence suggests, consumers' demand for housing is sufficiently inelastic, the rising price of residential investment and growing scarcity of land can account for most of the growth in housing's portion of capital income. Although this does not resolve all aspects of the time seriesespecially the fall and rise in the corporate sector-it does explain a sizable portion of the long-term contribution of housing.

Before the recent preeminence of the accumulation view, there were varied attempts to explain a falling labor share. Elsby, Hobijn, and Şahin (2013) highlighted the role of offshoring, while other papers emphasized 
additional structural and institutional forces. ${ }^{1}$ That literature does not apply directly here, since it uses gross concepts rather than net. Nonetheless, given the diverse accounts that have been proposed, it is no surprise that this paper fails to find a single mechanism that can explain the recent behavior of factor shares in its entirety.

The paper proceeds as follows. In section I, I discuss the conceptual basis of factor shares and provide evidence on the postwar path of the net capital share among G7 economies, including a decomposition that isolates the role of housing. In section II, I use a simple decomposition to analyze the trends in net capital share further, restricting the analysis to the United States to make use of more detailed data on capital stocks. In section III, I examine the canonical single-sector model, clarifying the difference between net and gross elasticities. In section IV, I integrate data and theory by building a multisector model, which refutes the accumulation view more definitively and supports the scarcity view as a partial alternative.

\section{Evidence on Factor Income Shares in Developed Countries}

In this section, I review the varying definitions of labor and capital share. I then examine a panel of $\mathrm{G} 7$ national accounts data to better understand how factor shares have evolved.

\section{I.A. Conceptual Issues}

The notion of a "labor" or "capital" share is not monolithic. There are several ways to define and measure these concepts, and different choices lead to strikingly different interpretations of the data.

DECOMPOSING GROSS VALUE-ADDED In the national accounts, the gross value-added of a sector at market prices - the value of its gross output, minus the intermediate inputs used in production — can be divided into three components: ${ }^{2}$ labor income (which includes both wages and supplementary compensation), taxes on production, and gross capital income (usually called "gross operating surplus" in the national accounts). Since the second component, taxes on production, does not accrue to either labor or capital,

1. See, for instance, Azmat, Manning, and Van Reenen (2012), who address the role of privatization, and Arpaia, Pérez, and Pichelmann (2009), who draw attention to capital-skill complementarity.

2. This decomposition potentially applies at many levels of aggregation: for instance, the "sector" may be the entire domestic economy, in which case gross value-added at market prices is called gross domestic product (GDP). 
when analyzing the distribution of income between factors it is often convenient to subtract this component, leaving us with gross value-added at factor cost. The latter can then be divided entirely into labor and gross capital shares, which sum to 1 . Since I focus in this paper on the division of income between capital and labor, I will generally use this approach.

It is important to recognize that the split of value-added between labor and capital is only the initial distribution. Labor income goes both to wages and to supplementary benefits, and a sizable share of wage income is subsequently paid to the government in taxes. Capital income is ultimately apportioned between many recipients, including the government (in the form of corporate and proprietor income taxes) and both debt and equity investors.

For instance, consider a sawmill. The gross value-added at factor cost is the difference between its sales of lumber and the cost of logs, excluding taxes on production. Once all compensation of employees at the sawmill is subtracted, the remainder is its gross capital income. Some of this capital income will be paid to lenders in the form of interest, some will be paid to the government in taxes on profits, and the rest may be retained on the balance sheet of the sawmill or distributed as dividends to shareholders. Gross capital income is thus a very broad concept, encompassing funds that are ultimately paid out to many different recipients-it is unaffected, for instance, by the split in financing between debt and equity. ${ }^{3}$

GROSS VERSUS NET: CONCEPTS An alternative to gross value-added is net value-added, which subtracts depreciation. This can be divided into labor and net capital income, the latter being gross capital income minus depreciation. Whether a gross or net measure is more appropriate depends on the question being asked. The allocation of gross value-added between labor and gross capital more directly reflects the structure of production, while the allocation of net value-added between labor and net capital reflects the ultimate command over resources that accrues to labor versus capital.

For instance, in an industry where most of the output is produced by short-lived software, the gross capital share will be high, evincing the centrality of capital's direct role in production. At the same time, the net capital share may be low, indicating that the returns from production ultimately go

3. This invariance can be very useful in analyzing trends-for instance, when high inflation pushes up nominal interest rates, a large share of capital income is often paid to bondholders in the form of nominal interest. As Modigliani and Cohn (1979) memorably observed in the context of late-1970s inflation, this causes recorded profits to dramatically understate true profits, since they do not reflect the gain from real depreciation in nominal liabilities. 
more to software engineers than to capitalists-whose return from production is offset by a loss from capital that rapidly becomes obsolete.

Both measures are important: indeed, a rise in the gross capital share in a particular industry is particularly salient to an employee whose job has been replaced by software, and it may proxy for an underlying shift in distribution within aggregate labor income-for instance, from travel agents to software engineers. The massive reallocation of gross income in manufacturing from labor to capital, documented by Elsby, Hobijn, and Şahin (2013), has certainly come as unwelcome news to manufacturing workers. But when one considers the ultimate breakdown of income between labor and capital, particularly in the context of concern about distribution in the aggregate economy, the net measure is likely more relevant. This point is affirmed by Piketty (2014), who uses net measures; the welfare relevance of net concepts is elucidated by Martin Weitzman (1976).

GROSS VERSUS NET SHARES: MEASUREMENT AND HISTORY Historically, the study of income shares has spanned both gross and net concepts: indeed, the famous quote by Keynes (1939) about the stability of labor's share referred to data on net shares, as did Kaldor's (1957) influential stylized fact.

More recently, however, the vast majority of work on the topicincluding Karabarbounis and Neiman's (2014a) well-known documentation of the declining global labor share-has examined gross shares. To a large extent, this is because gross shares are easier to measure and interpret: as economists since Michal Kalecki (1938) have observed, net income inherently involves a somewhat arbitrary computation of depreciation. High-quality data on gross shares are available for more countries, more years, and more levels of aggregation within each country.

Recently, debate has intensified about the empirical importance of this distinction. Bridgman (2014) argues that the inclusion of depreciationand, to a lesser extent, taxes on production-in the denominator of the labor share has caused economists to greatly overstate the magnitude and novelty of the labor share's decline. Augmenting their global data set with information on depreciation, Karabarbounis and Neiman (2014b) argue to the contrary that gross and net labor shares have mainly moved together, and that moving from gross to net shares at most moderately attenuates the downward trend. In my data analysis, I will focus on net shares, finding that the concerns in Bridgman (2014) are valid, especially in the years preceding the start of the Karabarbounis and Neiman (2014b) sample.

MIXED INCOME AND OTHER CONCERNS The distinction between gross and net is not the only concern when computing income shares. Another crucial problem is how to allocate "mixed" income_income earned by the 
self-employed that is recorded in the national accounts as going to capital. The central difficulty is that this income includes both returns to labor and returns to the capital investments made by the self-employed, with no data available to disentangle the two. This was an essential question for early students of the labor share in the United States: As D. Gale Johnson (1954) and others pointed out, the dramatic rise in workers' share of income in the first half of the twentieth century was in large part due to the shift from entrepreneurial income (often on farms) to formal labor income.

One solution is to disregard the entrepreneurial sector of the economy, for example by limiting attention to the labor share within the corporate sector. In any attempt to measure the labor share for the economy as a whole, however, some approach to dividing mixed income must be chosenand this choice can matter a great deal. Indeed, Elsby, Hobijn, and Şahin (2013) demonstrate that the headline measure provided by the Bureau of Labor Statistics most likely exaggerates the decline in the U.S. gross labor share due to weaknesses in its approach to imputing labor income for the self-employed. This approach assumes that the self-employed receive the same average compensation per hour as all other workers-an imputation that, although popular and tractable, has some unlikely implications for the U.S. data.

Alternative approaches to dividing mixed income, discussed by Douglas Gollin (2002), take several forms: they may involve doing a more sophisticated estimation of labor income for the self-employed based on personal characteristics, or assuming that the entrepreneurial sector has the same division between labor and capital as either some other sector or the economy as a whole. I follow Piketty and Zucman (2014) in adopting a form of the latter imputation, assuming that the noncorporate sector (excluding housing) has the same net capital share as the corporate sector.

Finally, another difficult point is the treatment of general government, as well as any other sectors whose output is valued in the national accounts "at cost"- - meaning that gross value-added is set equal to labor and depreciation costs-rather than by the market. Here, net capital income equals zero by construction; regardless, it is unclear what net capital income would mean in the context of government.

\section{I.B. Income Shares in the G7}

To better understand the recent evolution of factor shares, I turn to a panel with national accounts data from the G7, which consists of the United States, Japan, Germany, France, the United Kingdom, Italy, and Canada, currently the seven largest advanced economies by nominal GDP. Most 
of the data for the panel are derived from the Piketty and Zucman (2014) database, which in turn is taken directly from each country's national accounts publications.

Although this is a much narrower selection of countries than in the global panels of Karabarbounis and Neiman (2014a,b), it has several offsetting advantages. Most importantly, it covers a longer timespan: five countries have data starting in 1960 or earlier, and three countries have data starting in 1950 or earlier. ${ }^{4}$ By contrast, Karabarbounis and Neiman's (2014a,b) data set starts in 1975, and for many small and developing countries data only start becoming available much later. Since the net labor share in most countries was close to its postwar peak in the mid-1970s, this offers an incomplete view of the overall trend. The data set here also permits greater disaggregation, particularly along a dimension that will turn out to be crucial: housing versus the rest of the economy. By focusing on developed economies, it loses some generality but it stays closer to the contemporary debate about inequality and income distribution, which has mostly dealt with the developed world.

ESTIMATED AVERAGE SHARES To summarize the evolution over time of various income share measures $s_{i, t}$, I follow Karabarbounis and Neiman (2014a,b) by running panel regressions of the form

$$
s_{i, t}=\varphi_{i}+\alpha_{t}+e_{i, t}
$$

for countries $i$ and years $t$. I then display the yearly fixed effects $\alpha_{t}$, normalizing them so the fixed effect for the first year of the sample, $\alpha_{1948}$, equals the average share in the data set in 1948. ${ }^{5}$ I run both unweighted and weighted regressions; the weight for a country is its share of the sample's aggregate GDP in that year, as measured at PPP by version 8.0 of the Penn

4. The full set of start dates is 1948 (France, United Kingdom, United States), 1955 (Japan), 1960 (Canada), 1990 (Italy), and 1991 (Germany). Data for France, the United Kingdom, and the United States are available starting even earlier, but I focus on 1948 onward because that is when the necessary data start becoming available for my subsequent, more detailed exercise for the United States in section II. This also keeps the focus on postwar dynamics, detached from the sizable dislocations associated with depression and wartime, and mostly postdates the transition from agricultural self-employment to formal employment that bedeviled older analysts like Johnson (1954).

5. When countries have different trends in $s_{i, t}$, there will be an artifactual discontinuity in $\alpha_{t}$ when a country enters the sample, which in principle could deliver a misleading impression of the actual year-to-year changes in $s_{i, t}$. In practice, this does not seem to be much of an issue here, and alternative approaches - for instance, averaging the first differences $\Delta s_{i, t}$ across countries in the sample for each year $t$, then plotting the cumulative average first difference over time-deliver similar results. 
World Table. ${ }^{6}$ (For convenience, I will refer to these normalized time-fixed effects as yearly "averages.")

Unlike in the usual presentation, I deal with the capital share rather than its complement, the labor share. Of course, since I deal with value-added at factor cost, the capital share is always one minus the labor share; I focus on the former because I will emphasize the composition of capital income.

OVERALL CAPITAL SHARES: NET AND GROSS First I consider average capital shares for the private economy (excluding government, whose net capital share is zero by construction). As discussed in section I.A, I deal with the problem of self-employment income by following Piketty (2014) and Piketty and Zucman (2014) in the assumption that the net capital share in the noncorporate, nonhousing sector equals the net capital share in the corporate sector. ${ }^{7}$

Figures 1 and 2 report the average net and gross capital shares, respectively. As figure 1 demonstrates, the postwar behavior of the net capital share is characterized not so much by a secular rise as by a precipitous fall in the 1970s, which preceded a steady rebound. In this light, it is clear why Karabarbounis and Neiman (2014a,b) — with a sample starting in 1975, the year in which the unweighted estimate for the net capital share hits its minimum-observe such a dramatic and pervasive rise in capital income relative to labor.

Although Piketty (2014) and others have documented an overall U-shaped trend in the capital share, the claims about timing are quite different: for instance, Piketty (2014) observes that capital's aggregate valuation and share of income fell greatly in the first half of the twentieth century, during the depression and the two world wars. The postwar period is characterized as a period of recovery from this decline. Yet figure 1 shows that, if anything, the first half of the postwar era experienced a fall in the net capital share, and we are only today returning to levels achieved in the immediate aftermath of the war.

Set against figure 1, figure 2 reveals that there is a remarkable difference between the long-run behavior of net and gross shares, echoing the results of Bridgman (2014): since average depreciation as a share of gross valueadded has risen, the gross capital share displays much more of a longterm upward trend. Crucially, much of this disparity emerges before the

6. See Feenstra, Inklaar, and Timmer (2013).

7. There are two exceptions: the Canadian national accounts already provide a decomposition of mixed income into labor and capital, which I use; and the Japanese national accounts do not fully break out the corporate sector, necessitating some additional imputations. 
Figure 1. Average Net Capital Share of Private Domestic Value-Added, G7 Countries, 1950-2010

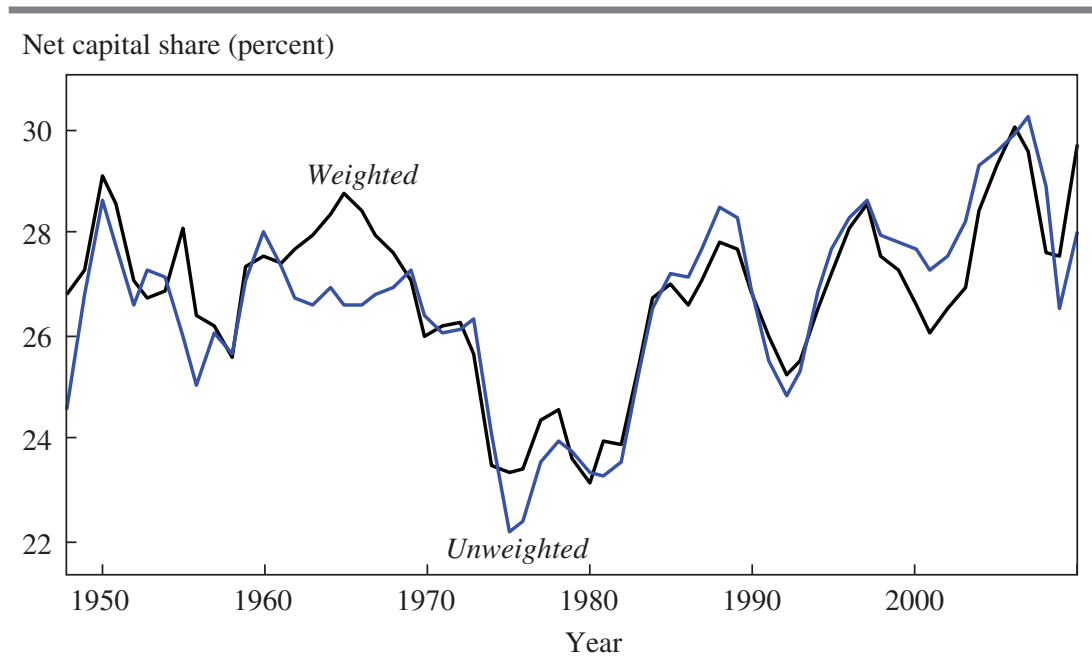

Source: Author's calculations based on national accounts; Piketty and Zucman (2014).

Figure 2. Average Gross Capital Share of Private Domestic Value-Added, G7 Countries, 1950-2010

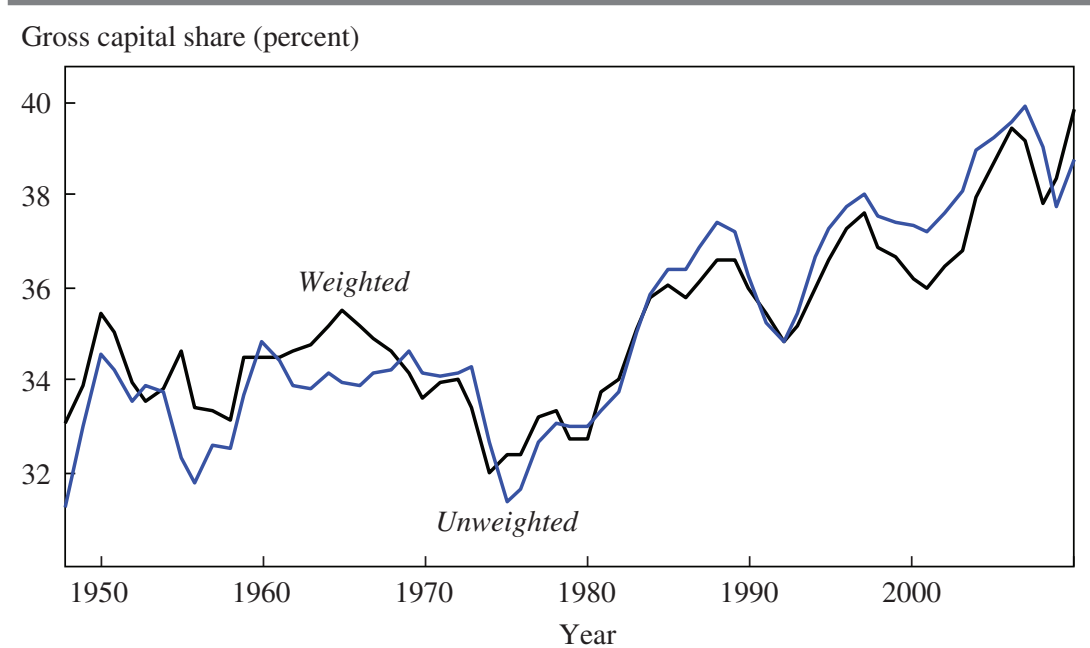

Source: Author's calculations based on national accounts; Piketty and Zucman (2014). 
Figure 3. Housing and Nonhousing Components of Average Net Capital Share of Private Domestic Value-Added, G7 Countries, 1950-2010

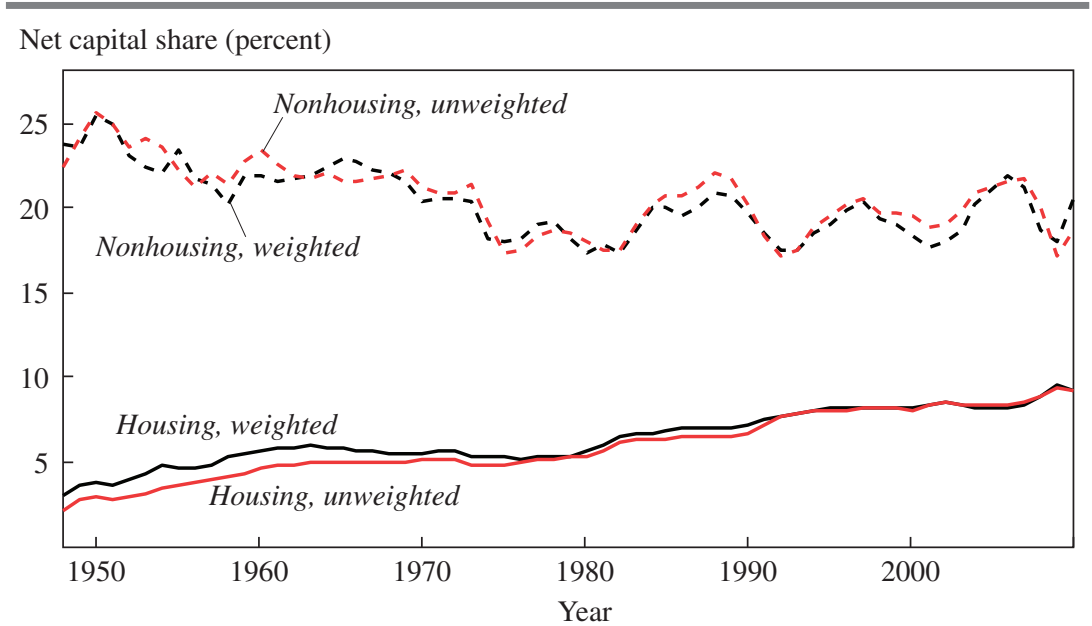

Source: Author's calculations based on national accounts; Piketty and Zucman (2014).

mid-1970s, perhaps explaining why Karabarbounis and Neiman (2014b) do not detect such an important role for depreciation in their sample. Given the unreliability of depreciation figures at high frequencies, the sudden rise in depreciation prior to the mid-1970s (which causes the divergence between gross and net) should not be given too much credence. The longterm rise in depreciation, however, appears much more robust. As Dongya Koh, Raül Santaeulàlia-Llopis, and Yu Zheng (2015) discuss, it is partly due to rapidly depreciating intellectual property-especially softwareincluded in the capital stock.

As I argued in section I.A, net shares are likely most relevant for discussions of distribution and inequality. Still, figure 1 paints a perhaps ambiguous picture of the net capital share: the recent rise might be in part just a recovery from the anomalously low levels of the 1970s, but the capital share is now reaching and even surpassing the heights previously achieved in the 1950s and 1960s. To what extent, then, is the current high share of capital income a truly novel phenomenon? This question is best addressed by disaggregating further along an important dimension, distinguishing between capital income from housing and capital income from the rest of the economy.

COMPOSITION OF THE NET CAPITAL SHARE: THE ROLE OF HOUSING Figure 3 subdivides the aggregate net capital share from figure 1 into two components: 
net capital income originating in the housing sector, and net capital income from all other sectors of the economy. ${ }^{8}$ It reveals that the aggregate net capital share originating in sectors other than housing has seen only a partial recovery since the 1970s; it remains below the levels of the 1950s, and slightly below or at par with the levels of the 1960s. In contrast, housing's contribution to net capital income has expanded enormously, from roughly 3 percentage points in 1950 to nearly 10 percentage points today.

Housing's central role in the long-term behavior of the aggregate net capital share demands careful scrutiny, yet it has not been emphasized elsewhere, to my knowledge. Income from housing is unlike most other forms of capital income recorded in the national accounts: in countries where homeownership is dominant, most output in the housing sector is recorded as imputed rent paid by homeowners to themselves. It may not be a coincidence that Germany, which table 1 reveals to have by far the lowest housing component of net capital income, also has the lowest homeownership rate in the G7. Indeed, imputed rents from owner-occupied housing should arguably be treated as a form of mixed income akin to self-employment income: in part, they reflect labor by the homeowners themselves. Figure 3 may therefore exaggerate the level of true "capital" income originating in the housing sector.

Nevertheless, even if figure 3 exaggerates the level of capital income from the housing sector, this does not necessarily explain the vast increase in housing capital income-unless the bias is greater today than in the past. One possible contributor to the trend could be a rise in the rate of homeownership; but this has not been nearly dramatic enough to account for a more than threefold increase in housing capital income. ${ }^{9}$ Another distinct source of bias could be rent control: if the rents imputed for homeowners in the national accounts improperly reflect controlled rents in the tenantoccupied sector, then the ebb and flow of rent regulations will have an inflated impact on income in the housing sector as a whole.

These possible biases notwithstanding, the main thrust of figure 3 is that housing plays a pivotal role in the modern story of income distribution. Since housing has relatively broad ownership, it does not conform to

8. For Canada and Japan, the "housing" sector is actually the owner-occupied housing sector due to data limitations. Importantly, Canada and Japan do not drive the trend here: to the contrary, from 1960 (when Canada enters the sample) to 2010, the average contribution of housing to net capital income in Canada and Japan increases by 3 percentage points, while in France, the United Kingdom, and the United States it increases by 4.5 percentage points.

9. See, for example, Andrews and Sánchez (2011) for some discussion of trends in homeownership. 
Table 1. Decadal Averages for the Net Capital Share of Private Domestic Value-Added, G7 Countries, 1950s to 2000s (Percent)

\begin{tabular}{llrrrrrr}
\hline & & $1950 s$ & $1960 s$ & $1970 s$ & $1980 s$ & $1990 s$ & $2000 s$ \\
\hline United States & Housing & 5.3 & 6.5 & 5.7 & 7.2 & 8.4 & 8.2 \\
& Other & 22.0 & 21.7 & 18.6 & 18.4 & 19.2 & 19.4 \\
\multirow{4}{*}{ Japan } & Total & 27.3 & 28.2 & 24.2 & 25.6 & 27.5 & 27.6 \\
& Housing & & 4.2 & 3.6 & 4.1 & 5.2 & 7.0 \\
& Other & & 31.2 & 26.9 & 25.7 & 21.6 & 20.1 \\
Germany & Total & & 35.4 & 30.5 & 29.8 & 26.9 & 27.1 \\
& Housing & & & & & 2.9 & 3.4 \\
\multirow{4}{*}{ France } & Other & & & & & 23.5 & 28.0 \\
& Total & & & & & 26.4 & 31.4 \\
& Housing & 3.6 & 5.1 & 5.9 & 7.1 & 9.8 & 10.8 \\
United Kingdom & Other & 21.3 & 19.8 & 17.9 & 16.6 & 19.9 & 18.0 \\
& Total & 24.9 & 24.9 & 23.8 & 23.7 & 29.7 & 28.8 \\
& Housing & 1.2 & 2.1 & 3.8 & 4.6 & 5.8 & 7.3 \\
& Other & 27.2 & 23.9 & 18.3 & 21.6 & 23.2 & 23.4 \\
Italy & Total & 28.4 & 26.0 & 22.1 & 26.2 & 29.0 & 30.7 \\
& Housing & & & & & 4.3 & 6.4 \\
& Other & & & & & 33.9 & 32.5 \\
Canada & Total & & & & & 38.2 & 38.9 \\
& Housing & & 6.6 & 6.6 & 8.1 & 10.4 & 8.6 \\
& Other & & 22.5 & 24.0 & 25.8 & 21.2 & 27.2 \\
& Total & & 29.1 & 30.6 & 33.8 & 31.6 & 35.8 \\
\hline
\end{tabular}

Source: National accounts; Piketty and Zucman (2014).

the traditional story of labor versus capital, nor can its growth be easily explained with many of the stories commonly proposed for the income split elsewhere in the economy, such as the bargaining power of labor and the growing role of technology.

The divergence between housing and other forms of capital is also hard to reconcile with the accumulation view. In the Piketty (2014) narrative, for instance, it is not clear why a rise in the aggregate wealth-to-income ratio should be channeled entirely into a rise in the housing component of the net capital share while the non-housing component stagnates. ${ }^{10}$

NET CAPITAL SHARE WITHIN THE CORPORATE SECTOR For additional clarity, figure 4 plots the average net capital share within the corporate sector. Restricting attention to the corporate sector is a common way to deal with perceived conceptual and measurement difficulties elsewhere in the

10. In fact, computations using the multisector model in section IV.B will show that this is backward: the fall in $r$ induced by savings should lead to a concentrated decline in the housing component of the net capital share. 
Figure 4. Average Net Capital Shares of Corporate Sector Value-Added, G7 Countries. 1950-2010

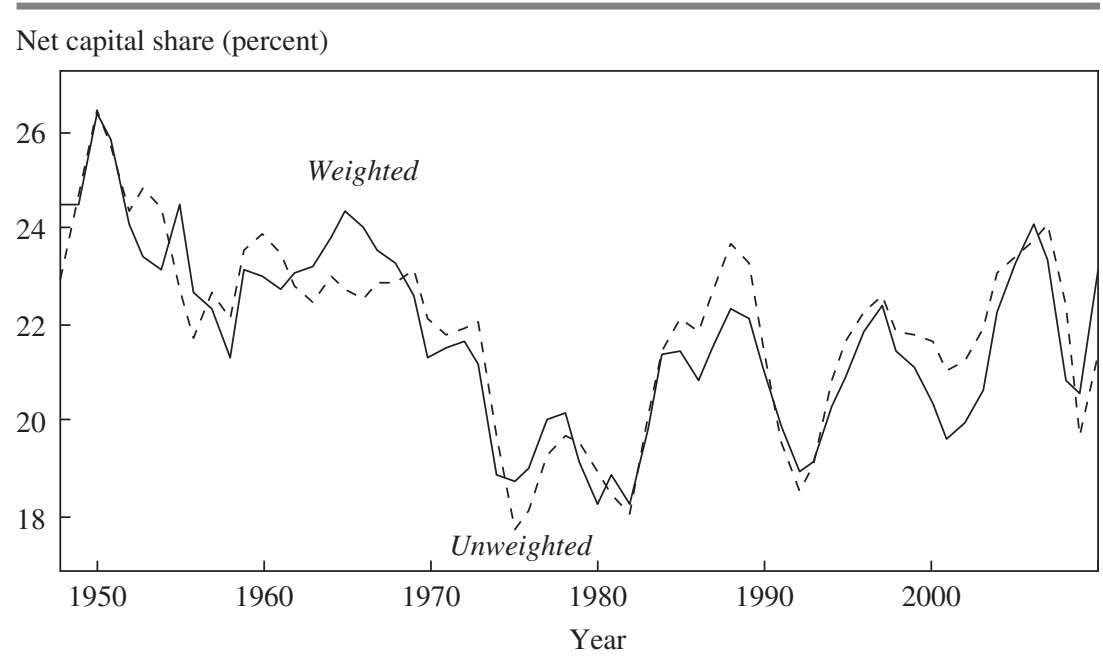

Source: Author's calculations based on national accounts; Piketty and Zucman (2014).

economy - including ambiguity in the labor/capital split of mixed incomeas well as with the crucial role of housing. Figure 4 echoes the behavior of the nonhousing component in figure 3 , with a sustained fall until the 1970s and a partial recovery in the decades since. Indeed, this resemblance is no coincidence: as discussed above, figure 3 imputes the net capital share in the nonhousing, noncorporate sector to be the same as in the corporate sector, so that movement in all nonhousing capital income is fundamentally driven by the corporate capital share visible in figure $4 .{ }^{11}$

Although it does not show any decisive, long-term trend, figure 4 does clash with Kaldor's (1957) view of stable income shares. It also contrasts with the relatively steady upward creep of housing capital income shown in figure 3. Fluctuations in the average corporate capital share have been rapid and macroeconomically significant—dropping from a high around 26 percent in 1950 to a trough around 18 percent in the 1970s and 80s and then rebounding to a peak of 24 percent in the 2000s. Indeed, the fall in the unweighted average share from 26.4 percent in 1950 to 17.7 percent in

11. As described in footnote 7 , different imputations are used for Canada and Japan. Furthermore, since separate data for the corporate sector are not available in Japan, figure 4 displays the overall capital share for Japan instead. 
Table 2. Decadal Averages for the Net Capital Share of Value-Added in the Domestic Corporate Sector, G7 Countries, 1950s to 2000s (Percent)

\begin{tabular}{lcccccc}
\hline & $1950 s$ & $1960 s$ & $1970 s$ & $1980 s$ & $1990 s$ & $2000 s$ \\
\hline United States & 23.2 & 23.2 & 19.7 & 19.8 & 20.9 & 21.1 \\
Germany & & & & & 24.2 & 29.0 \\
France & 22.1 & 20.9 & 19.0 & 17.9 & 22.1 & 20.1 \\
United Kingdom & 27.6 & 24.4 & 19.0 & 22.7 & 24.7 & 25.3 \\
Italy & & & & & 35.4 & 34.6 \\
Canada & & 24.5 & 26.1 & 28.5 & 24.3 & 30.1 \\
\hline
\end{tabular}

Source: National accounts; Piketty and Zucman (2014).

1975, all else equal, contributed nearly half a percentage point annually to growth in corporate labor compensation during that interval. In contrast, the rapid rise from 17.7 percent in 1975 to 23.6 percent in 1988 subtracted slightly more than half a percentage point of annual compensation growth. ${ }^{12}$

Over the long term, however, the role of fluctuating corporate income shares is comparatively quite mild. For both the weighted and unweighted averages, the impact on annual compensation growth from the 1948-2010 change in net shares is roughly three-hundredths of a percentage point..$^{13}$ The overall message is clear, and arguably consistent with the Kaldor (1957) perspective on long-run growth: changes in the distribution of corporate income-even systematic ones spread across several countries-can have a marked effect on the short-to-medium-run growth of paychecks. The impact on long-run labor compensation, however, appears to be little more than a rounding error when set against trend growth. ${ }^{14}$ (See table 2.)

There is also a pronounced cyclical pattern in figure 4. This has long been recognized: the labor share tends to rise late in expansions and fall late in recessions. The economic explanation for this pattern, however, is

12. Explicitly, $((1-.177) /(1-.264))^{(1 / 25)}-1 \approx .45 \%$ and $((1-.236) /(1-.177))^{(1 / 13)}-$ $1 \approx-.57 \%$.

13. Explicitly, for unweighted: $((1-.214) /(1-.229))^{(1 / 62)}-1 \approx .03 \%$. For weighted: $((1-.231) /(1-.245))^{(1 / 62)}-1 \approx .03 \%$.

14. To be clear, the long-run impact in individual countries can be larger. Perhaps the most extreme example is Japan, which table 1 shows to have experienced a decline in the average nonhousing share of aggregate capital income from 31 percent in the 1960s to 20 percent in the 2000s, implying an annualized contribution to wage growth of roughly three-tenths of a percentage point. But table 2 does not suggest any long-run tendency for corporate capital shares in different countries to diverge from each other; the distinct paths across countries are therefore probably best interpreted as mean-reverting variations around an apparently trendless average. 
somewhat harder to discern. Conventional wisdom is that low unemployment puts upward pressure on real wages and hence the labor share, while high unemployment keeps real wage growth subdued. This story, however, implicitly involves variation in markups: as Mitchell (1941, p. 54) observes, "a problem still remains: Why cannot businessmen defend their profit margins against the threatened encroachment of costs by marking up their selling prices?" Answering this challenge, the business cycle literature offers an abundance of proposed explanations for the cyclical pattern of markups, of which Rotemberg and Woodford (1999) provide an excellent summary.

\section{Decomposing the Capital Share}

In this section I decompose the net capital share by disaggregating fixed capital into its most important components and determining the share of capital income attributable to each as well as the share coming from markups. I apply this decomposition first to the corporate sector and then to the private domestic economy as a whole.

\section{II.A. Bringing in the Value of Capital}

My discussion in section I provided some preliminary insights into the structure of the net capital share by distinguishing between its housing and nonhousing components. That examination found that the housing component has seen a steady increase, while the nonhousing component has experienced a dramatic fall and then a rise. To better understand these movements, it is important to look at another piece of evidence: the value of the capital stock itself.

Both the Piketty (2014) and Karabarbounis and Neiman (2014a) versions of the accumulation view, for instance, explain the recent rise in the capital share through a rise in the value of reproducible capital relative to aggregate income. In fact, this is a central feature of virtually any narrative that stresses capital accumulation: if capital is earning a larger share because we are building more of it, then data on the value of capital should reveal that it has indeed grown relative to income.

Furthermore, this should be true within sectors. For instance, if accumulation explains the rise in the nonhousing capital share over the last few decades, then one should see a rising value of capital within the nonhousing sector relative to sectoral value-added. This is a simple but crucial check. Elaborating upon it, we can try to disentangle the roles of three different influences on the capital share: the observed value of capital itself; the net user cost of that capital; and firms' markups over cost that lead to 
additional capital income, not attributable to the user cost of the measured capital stock.

THEORY Formally, let $K_{1}, \ldots, K_{n}$ be different types of capital, and let $Y=F\left(N, K_{1}, \ldots, K_{n}\right)$ be a constant-returns-to-scale production function that takes labor $N$ and capital $K_{1}, \ldots, K_{n}$ as inputs. Suppose that output $Y$ is sold at a price $P$ that represents a markup of $\mu \geq 1$ over the cost of production, ${ }^{15}$ such that the share of what I will call "pure profits" (capital income above and beyond the user cost of capital $K_{1}, \ldots, K_{n}$ ) in gross income is $\pi \equiv 1-\mu^{-1}$. I allow for a potentially time-varying markup $\mu$ in part because of the discussion of the corporate capital share in section I.B, which notes a pronounced cyclical pattern that has been explained in the literature through markup variation.

Letting $W_{N}$ denote the wage paid to labor and $W_{K_{1}}, \ldots, W_{K_{n}}$ denote the user costs of capital, we have

$$
(1-\pi) P Y=W_{N} N+\sum_{i=1}^{n} W_{K_{i}} K_{i} .
$$

Suppose further that the model is cast in continuous time (suppressing time subscripts for convenience), and that the flow real cost of funds is $r$. Capital $K_{i}$ has real price $P_{i}$, with expected real growth rate $g_{P_{i}}$, as well as a flow depreciation rate of $\delta_{i}$. The user cost $W_{K_{i}}$ is then

$$
W K_{i}=P_{i}\left(r+\delta_{i}-g_{P_{i}}\right),
$$

reflecting the real cost $P_{i} r$ of financing each unit of capital and the expected combined effect $P_{i}\left(\delta_{i}-g_{P_{i}}\right)$ of depreciation and price growth on the value of capital held.

Combining equations 1 and 2, we see that we can divide net output into labor income $W_{N} N$ and net capital income; the latter can further be divided into a share $\pi P Y$ of profits and a component $\left(r-g_{P_{i}}\right) P_{i} K_{i}$ corresponding to each type of capital $i$ :

$$
\underbrace{P Y-\sum_{i}^{n} \delta_{i} P_{i} K_{i}}_{\text {net output }}=W_{N} N+\underbrace{\pi P Y+\sum_{i=1}^{n}\left(r-g_{P_{i}}\right) P_{i} K_{i}}_{\text {net capital lincome }} .
$$

15. Since $F$ is constant-returns-to-scale, marginal and average costs are equal, so I will refer to them both as "cost." 
Letting $Y^{\text {net }}$ denote net output on the left of equation 3, we can divide through by $Y^{\text {net }}$ to write equation 3 in terms of shares:

$$
1=\underbrace{W_{N} N / Y^{\text {net }}}_{\text {net labor share }}+\underbrace{\pi P Y / Y^{\text {net }}+\sum_{i=1}^{n}\left(r-g_{P_{t}}\right)\left(P_{i} K_{i} / Y^{\text {net }}\right)}_{\text {net capial share }} .
$$

Equation 4 illustrates formally how we can divide the net capital share into components that reflect the ratio $P_{i} K_{i} / Y^{\text {net }}$ of the value of capital of each type $i$ to net income. As discussed earlier, this allows us to evaluate a central element of the accumulation view-namely, that changes in $P_{i} K_{i} / Y^{\text {net }}$ have played a key role in the evolution of the net capital share.

DISCUSSION OF IMPLEMENTATION Suppose that in practice we have disaggregated capital into $n$ types, for which we have data on the value $P_{i} K_{i}$, and we want to divide the observed capital share of net income $Y^{\text {net }}$ into the components identified in equation 4. First, expected price growth $g_{P_{i}}$ is needed; this is very difficult to obtain in principle, since we rarely observe agents' individual expectations of price growth, but it can be roughly approximated by assuming that $g_{P_{i}}$ matches the trend rate of growth over some interval.

The most difficult parts of equation 4 are $\pi$ and $r$ : with knowledge of one, we can infer the other, but neither is readily available in the data. In principle, $r$ could be obtained from financial markets, perhaps as some function of bond and equity prices. But this is a notoriously hard problem: it is challenging to know exactly how the costs of borrowing or equity finance map onto the effective cost of funds faced by an enterprise. Furthermore, since this $r$ is pretax while returns on bonds or equity are after corporate taxes, a time-varying tax adjustment would be needed to infer $r$ directly from market returns.

\section{II.B. Implementation: Decomposing the Net Corporate Capital Share, 1948-2013}

I first attempt the disaggregation in equation 4 for the net capital share in the U.S. corporate sector, at an annual frequency for the years 1948 through 2013. ${ }^{16}$ I disaggregate fixed capital into its three most important components: structures, equipment, and land (denoted by $i=s, e, l$ ), and I obtain the values $P_{i} K_{i}$ for the corporate sector from the the Financial Accounts of

16. Ideally, this exercise would extend to all seven of the G7 countries covered in section I, but the additional data required make this difficult. 
the United States. ${ }^{17}$ I assume that the expected price growth $g_{P_{i}}$ of each form of capital is its actual average real price change from the end of 1947 to the end of 2013. I then try several approaches to resolving the difficulties identified at the end of section II.A above.

EVALUATING THE ACCUMULATION VIEW: ASSUMING CONSTANT " $r$ " One way to implement the decomposition in equation 4 is to simply impose constant $r$. Taken literally, this is probably not a viable assumption, but it is a straightforward approach to testing the accumulation view: if we rule out variation in $r$ as a source of change in equation 4, how much of the time series can $P_{i} K_{i} / Y^{\text {net }}$ itself explain? How well do movements in $P_{i} K_{i} / Y^{\text {net }}$ correlate with changes in the net capital share, and what role can they play quantitatively when $r$ is chosen to be of reasonable size?

Note that in this exercise, the "pure profit" term $\pi P Y / Y^{\text {net }}$ is effectively just a residual. The goal, for now, is not to provide a complete and convincing decomposition of the net capital share into changes in $\pi, r$, and $P_{i} K_{i} / Y^{\text {net }}$ but, instead, to see what role $P_{i} K_{i} / Y^{\text {net }}$ alone can play. This exercise, though similar, is more informative than mere inspection of the paths of $P_{i} K_{i} / Y^{\text {net }}$ relative to the path of the net capital share, because it provides some indication of magnitude. For instance, if $P_{i} K_{i} / Y^{\text {net }}$ moves together with the net capital share for most $i$, this pattern would appear consistent with the accumulation view. However, to see whether this support is quantitatively viable, it is necessary to map the changes in $P_{i} K_{i} / Y^{\text {net }}$ onto their contributions to the net capital share. This is the role of equation 4 , together with some choice of constant $r$.

First, I assume that $r$ takes a constant value over the sample period 1948-2013 such that the average profit share $\pi$ of corporate revenue over the sample is zero. This implies $r \approx 11$ percent. ${ }^{18}$ Effectively, the assumption here is that in the long run, there are no pure profits in the corporate sectoron average, net capital income reflects a return on equipment, structure, or land. This is consistent with Chamberlinian monopolistic competition, where entry drives monopoly profits to zero, on average, in the long run.

17. Since the flow of funds provides end-of-year values for capital, I average the adjacent end-of-year values to obtain the effective capital stock used in production during each year.

18. Although this seems high for a real return, note that it is a pretax return, the return before taxes are applied either to corporate profits or distributions of interest or dividends. Interestingly, it is slightly lower than the constant return in figure 7 estimated using my alternative approach, which is roughly 12.8 percent. As explained later in this paper, this return is higher because according to the flow of funds, the total market value of the corporate sector in the United States has actually been lower than the book value, on average, in the postwar erasuggesting that pure profits are, if anything, negative, and that the assumption that pure profits are zero on average is not misattributing these profits to an exaggerated return $r$ on capital. 
Figure 5. Net Capital Share of Corporate Sector Value-Added, United States, 1950-2010

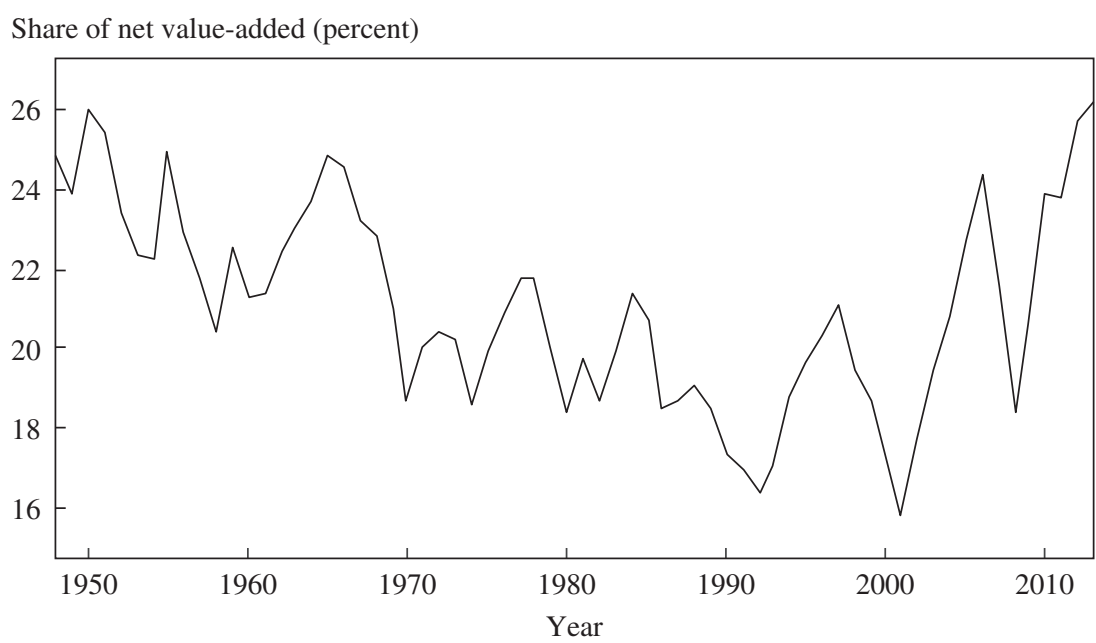

Source: National Income and Product Accounts.

Figure 6 shows how the net capital income for the U.S. corporate sector in figure 5 breaks down into the four components in equation 3 under this assumption. Though there are some fluctuations in each component's contribution, both the U-shaped pattern and the cyclical fluctuations in the corporate capital share in figure 5 appear dominated by the residual component of "pure profits" $\pi$. In other words, contrary to the accumulation view, time-series shifts in the capital share in the corporate sector cannot be explained by parallel shifts in the measured value of capital.

CONSEQUENCES FOR THE FALLING-INVESTMENT-PRICES HYPOTHESIS As figure 6 further reveals, the contribution from equipment in particular is, if anything, the inverse of the U-shaped pattern in the corporate net capital share in figure 5: it rises in the 1970s and 1980s, and then later trends downward. Since equipment is the component of fixed capital that has experienced a decline in real price,,$^{19}$ this is hard to reconcile with a central role for falling investment prices in the dynamics of capital's share, the hypothesis emphasized by Karabarbounis and Neiman (2014a). Without a structural model, of course, this exercise is not decisive: falling investment prices might contribute to a rising capital share through some more indirect causal channel, and indeed Karabarbounis and Neiman (2014b) suggest

19. The equipment investment deflator rose relative to the GDP deflator at an annualized rate of 1.5 percent during the sample period, as opposed to a 1.1 percent average rise in the deflator for nonresidential structures. 
Figure 6. Decomposition of Net Capital Share of Corporate Sector Value-Added, United States, 1950-2010

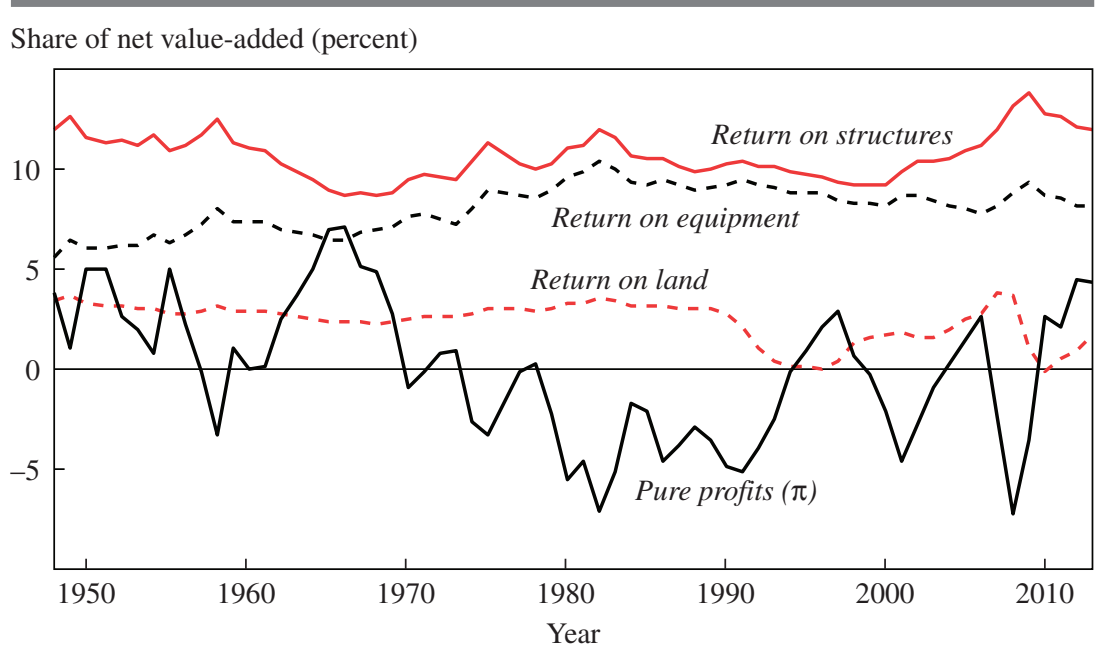

Source: Author's calculations based on National Income and Product Accounts, Financial Accounts of the United States.

one such possibility. I address these concerns with a multisector model in section IV.B, where I generally do not find a major role for such indirect mechanisms.

Surprisingly, my finding here is consistent with the result of a closely related exercise in section IV.B of Karabarbounis and Neiman (2014a), who also decompose nonlabor income into a component reflecting the return on accumulated capital and a component reflecting markups, under the assumption of a constant real interest rate. Although it is not their focus, Karabarbounis and Neiman (2014a) remark that they generally do not find increases in the share of the former component. This implies that the fall in labor share comes in the aggregate from the rise in markups rather than from returns on measured capital.

At face value, this contradicts the emphasis on capital accumulation as a source of the falling labor share. However, Karabarbounis and Neiman (2014a) point out that if their elasticity estimate is valid, it remains correct to say that counterfactually, the labor share would be higher if not for the role of falling investment prices in encouraging investment. Of course, if that is true, it follows that there must be two other unidentified forces influencing the factor distribution of income: (i) some force of similar magnitude that offsets their mechanism in the aggregate by pushing investment 
downward, and (ii) another force leading to the rise in markups, which accounts for the entire aggregate fall in the labor share. With these forces in play, the accumulation view only plays a secondary role, regardless.

SMALLER " $r$ " Figure 5 can also be constructed assuming a smaller $r$, under the assumption that pure profits in the corporate sector are not all dissipated in the long run. This does not materially change the conclusion that the measured value of capital is unable to account for the major shifts in the net capital share. (Indeed, a smaller $r$ in equation 4 directly leads to a lower weight on $P_{i} K_{i} / Y^{\text {net }}$.)

STRUCTURAL APPROACH: IDENTIFY TIME PATH FOR " $r$ " FROM MARKET MINUS BOOK VALUE In an attempt to more convincingly disentangle the roles of $r$ and $\pi$, I turn to a more elaborate approach for estimating $r$. The basic idea is that the difference between the market value of corporations and the value of their fixed assets should reflect the expected stream of future pure profits $\pi P Y$ (perhaps up to some stochastic pricing error). We can use this observation as a strategy to estimate the implied $r$. For instance, if the market value is much higher than the value of the firm's assets, the expected stream of pure profits $\pi P Y$ is high, and $r$ in the future must be low enough that there are pure profits left over in equation 3 after the direct return from capital $\Sigma_{i}\left(r-g_{P_{i}}\right) P_{i} K_{i}$ is subtracted. ${ }^{20}$

DESCRIPTION OF THE METHOD The online appendix provides the technical details, along with the specific theoretical assumptions in a continuoustime model that are needed to make the procedure valid..$^{21}$ The core equation implied by the theory (see appendix equations 32 and 33) is this:

$$
\mathbb{E}\left[\frac{\phi(t)}{\text { output between } t-1 \text { and } t} \times\left(\begin{array}{c}
O M V(t)-\text { discount } \\
\times O M V(t+1)
\end{array}\right)\right]
$$

$=\mathbb{E}\left[\frac{\phi(t)}{\text { output between } t-1 \text { and } t} \times\right.$ pure profits between $t$ and $\left.t+1\right]$,

where $O M V(t)$ denotes the difference between the market value and book value of corporations recorded at time $t$, and $\phi(t)$ is an arbitrary time-dependent function. Implicit in equation 5 is a nonstochastic time

20. For simplicity, I will call the total value of the firm's fixed assets its "book value," even though this is not necessarily book value in the usual sense: I will define it to exclude financial assets-these are instead subtracted from the market value, which includes net financial liabilities - and to use values from the flow of funds for real estate and equipment, which are updated to reflect changes in price.

21. Online appendixes for papers in this volume may be found at the Brookings Papers web page, www.brookings.edu/bpea, under "Past Editions." 
path $r(t)$ for the real interest rate, which is needed to calculate profits $\pi(t)$ $P(t) Y(t)$ as a residual in equation 3 and to calculate the proper discount factors.

The interpretation of equation 5 is straightforward: it states that the expected difference between the present value of next year's excess market value $O M V(t+1)$ and this year's excess market value $O M V(t)$ reflects expected pure profits between $t$ and $t+1$. This relation continues to hold, in expectation, when both sides are normalized by the previous year's recorded output, which I do to render values comparable across time. It also holds when both sides are multiplied by any choice of the time-dependent function $\phi(t)$. Technically speaking, equation 5 can be used as a moment condition to estimate $r(t)$.

If we have $n$ functions $\left\{\phi_{1}(t), \ldots, \phi_{n}(t)\right\}$, we obtain $n$ distinct moment conditions (equation 5) and can enforce these conditions in the sample to solve for an $n$-parameter functional form for $r(t)$. I choose $\phi_{1}(t)=1$, $\phi_{2}(t)=t$, and $\phi_{3}(t)=t^{2}$, and estimate three specifications for $r(t)$ : a constant value $r(t)=\bar{r}$, a linear trend $r(t)=a_{0}+a_{1} t$, and a quadratic trend $r(t)=a_{0}+a_{1} t+a_{2} t^{2}$ using the moment conditions implied by $\left\{\phi_{1}(t)\right\}$, $\left\{\phi_{1}(t), \phi_{2}(t)\right\}$, and $\left\{\phi_{1}(t), \phi_{2}(t), \phi_{3}(t)\right\}$, respectively.

Effectively, I am solving for the constant $\bar{r}$ such that the expression

$$
\frac{O M V(t)-\text { discount } \times O M V(t+1)-\text { pure profits between } t \text { and } t+1}{\text { output between } t-1 \text { and } t}
$$

equals zero on average throughout the sample; and I am also solving for the linear $r(t)=a_{0}+a_{1} t$ and the quadratic $r(t)=a_{0}+a_{1} t+a_{2} t^{2}$ such that equation 6 does not have any linear or quadratic trends over time, respectively.

When calculating $O M V$, the difference between the market value of the corporate sector and the book value of its fixed capital, I interpret the "market value" to be the total value of all financial claims on a corporation - both its equity market capitalization and its net financial liabilities - in order to be consistent with the computation of capital income in the national accounts, which includes income that ultimately goes to both shareholders and bondholders. ${ }^{22}$ Both market and book value are taken from the Financial Accounts of the United States.

22. This causes some anomalies in the early postwar years, when the corporate sector was left with large cash balances and relatively little debt, making net liabilities negative while equity valuations were already quite low, and leading to an extremely low market relative to book value. To avoid undue influence from this period, I exclude data from prior to 1955 in the benchmark results displayed here; otherwise, there is an even more dramatic estimated downward trend in $r(t)$. 
Figure 7. Estimated Constant, Linear, and Quadratic Time Trends for the Corporate Rate of Return $r(t)$

Estimated corporate return $r$ (percent)

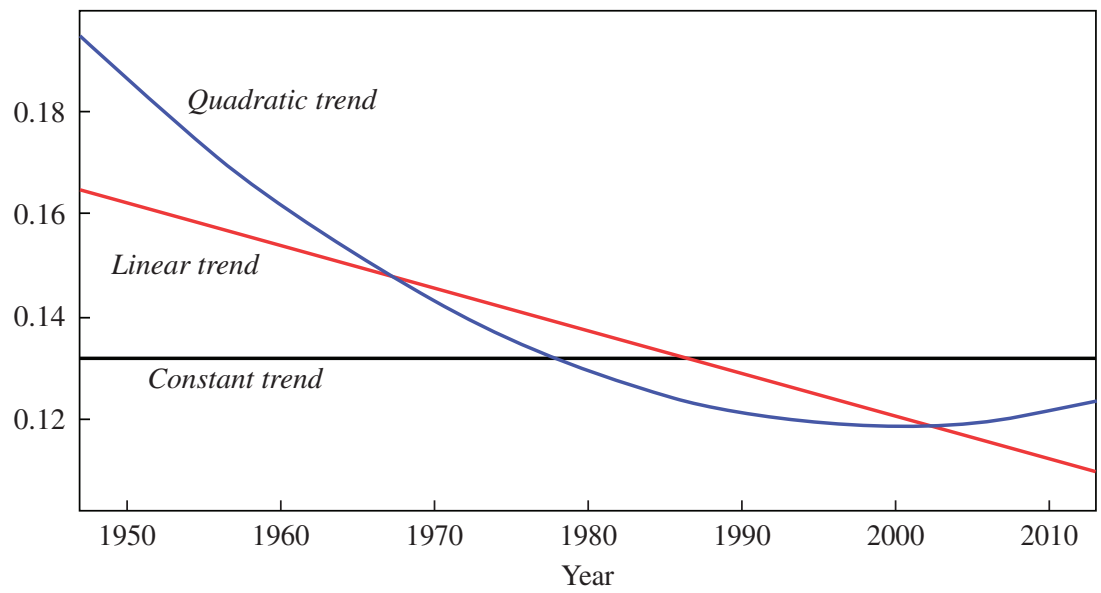

Source: Author's calculations; see text for details.

ESTIMATED PATHS FOR " $r$ " Figure 7 shows the estimated constant, linear, and quadratic time trends for the corporate rate of return $r(t)$ following the procedure above. The most striking feature of these plots is the general downward trend in $r(t)$ : according to this procedure, the required return on capital for the U.S. corporate sector has fallen over the postwar era. This reflects the fact that the market value of corporations has grown relative to book value over this period, albeit unevenly, as can be seen in figure 9. The estimation infers from this that pure profits are trending upward, so that the required return on capital $r(t)$ itself must be declining.

Another interesting feature of figure 7 is that the estimated constant $\bar{r}$, at roughly 12.8 percent, is actually higher than the $r$ chosen in my benchmark decomposition to set the average share of pure profits to zero. This reflects the fact that according to the Financial Accounts of the United States, on average, the aggregate market value of corporations has actually been slightly below the book value during the sample period, as depicted in figure 9. This suggests that the assumption of zero average pure profits for the benchmark decomposition was not too far out of line: corporations, on average, have not been worth more than the underlying value of their assets. 
Since I am only estimating parametric trends for $r(t)$ here, I am not allowing $r(t)$ to vary at high frequencies with the business cycle; market prices at high frequencies are too noisy and volatile to permit credible estimation of $r(t)$ using the method above. This means that I still cannot address, for instance, the role played by cyclical fluctuations in $r(t)$ in driving cyclical fluctuations in the capital share. But by allowing for a long-term trend in $r(t)$, I can disentangle the long-term effects of $r$ from the effects of changing capital-income ratios $P_{i} K_{i} / Y^{\text {net }}$, and obtain a better assessment of the role of pure profits $\pi P Y / Y^{\text {net }}$.

Since the long-term trend in the corporate net capital share is U-shaped, with a large fall and recovery, I will emphasize the results from the quadratic estimated trend $r(t)$. To the extent that varying $r$ is partly responsible for the U-shaped trend, quadratic $r(t)$ can capture much of its impact.

IMPLICATIONS OF QUADRATIC TREND IN " $r$ " Redoing the decomposition in figure 6 , using the quadratic trend for $r(t)$ rather than a constant, produces figure 8 . The impact of the change in $r(t)$ is unsurprising. Relative to figure 6 , figure 8 initially attributes a larger share of returns to fixed capital, offset by substantial negative pure profits; over time, the return on fixed capital falls, and the role of pure profits grows substantially. As in figure 6, pure profits play a central role in the U-shaped path for the overall corporate net capital share-but these movements come in addition to broad offsetting trends, in which pure profits have replaced income from fixed assets in equation 3.

It is difficult to say how literally these trends should be interpreted. Given the methodology for identifying $r(t)$, they are ultimately the consequence of the long-term rise in the ratio of market value to book value in the U.S. corporate sector, as seen in figure 9. This, in turn, may be the result of other, unmodeled changes in financial markets, not a rise in $\pi$. Nevertheless, figure 8 is certainly suggestive, and it casts additional doubt on the accumulation view, since it indicates that, contrary to the assumption of relatively stable returns per dollar of capital, $r(t)$ has experienced a sizable decline.

\section{II.C. Extending the Decomposition: The Net Capital Share for the Private Economy}

I now extend the decomposition in section II.B to the net capital share for the private domestic economy as a whole-excluding the nonhousing government and NPISH (nonprofit institutions serving households) sectors, which have zero net capital share by construction in the national accounts. 
Figure 8. Decomposition of Net Capital Share of Corporate Sector Value-Added, Using Quadratic Trend for $r(t)$, United States, 1950-2010

Share of net value-added (percent)

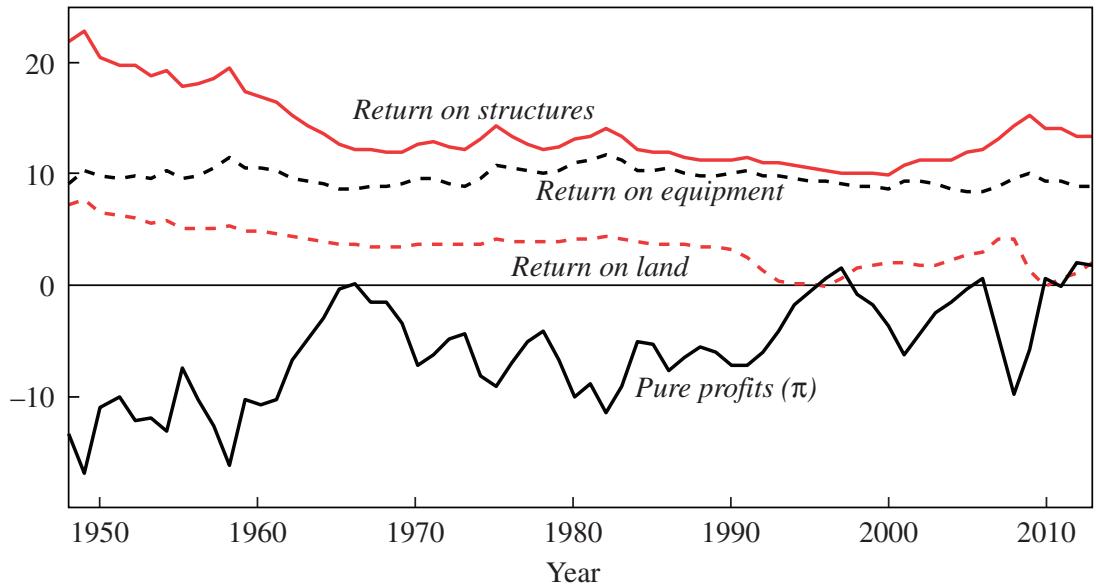

Source: Author's calculations based on National Income and Product Accounts, Financial Accounts of the United States.

Figure 9. Ratio of Total Market Value to the Recorded Value of Equipment, Structures, and Land, U.S. Corporate Sector, 1950-2010

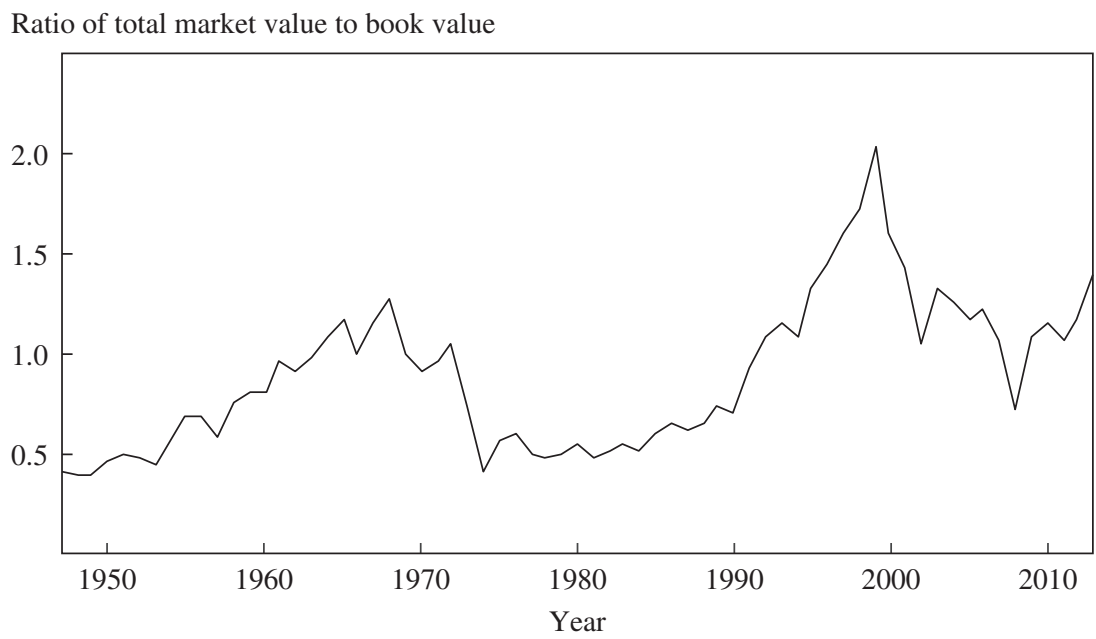

Source: Financial Accounts of the United States. 
Due to the inherent difficulties in apportioning mixed income between labor and capital, as discussed in section I.A, this requires some imputations. I will assume that both the rate of return $r$ and the pure profit share $\pi$ are the same in the nonhousing, noncorporate sector and the corporate sector, and use the estimated quadratic path for $r$ from the previous section. ${ }^{23}$ For the housing sector, I will assume that there is no pure profit. I allow $r$ to vary over time in equation 3 such that net housing capital income always equals $\left(r-g_{P_{s 2}}\right) P_{s 2} K_{s 2}+\left(r-g_{P_{12}}\right) P_{l 2} L_{2}$, where $P_{s 2} K_{s 2}$ is the value of residential structures and $P_{12} L_{2}$ is the value of residential land.

The results are displayed in figure 11, which decomposes the net capital share displayed in figure 10. Figure 11 is noisy, and for the most part it combines the lessons from sections I.B and II.B. It shows a strong, long-term upward trend in net capital income from housing, and the volatile capital share elsewhere in the economy is driven principally by pure profits.

There are, however, some additional insights in the figure 11 decomposition. For instance, the rise in net income for the housing sector has come both from residential structures and from land, but figure 11 attributes a larger portion of the increase (and of the level) to structures.

This may come as a surprise, since one plausible hypothesis for the growth of net housing income is the rising scarcity of land. In part, the secondary role of residential land here comes from its more rapid price appreciation. Since I assume that the net rate of return including expected capital gains is equalized between residential structures and land, the net rate of return excluding expected capital gains-which is used in the decomposition because income in the national accounts also excludes capital gainsis significantly lower for land. In a sense, then, the lesser role of land is due to the idiosyncrasies of national accounting; an alternative definition of net capital income that included some form of expected capital gains would show a larger impact from land. (With this in mind, it is remarkable that housing plays such a large aggregate role in section I.B already: if the G7 national accounts data were modified to include capital gains, housing's centrality would only increase.)

23. Note that this imputation, which uses data on the value of fixed assets in the noncorporate sector, is different from the imputation in section I.B, where these data were not available for the full sample and the net capital share of income-rather than the return $r$ in the nonhousing, noncorporate sector was assumed to be the same as in the corporate sector. 
Figure 10. Net Capital Share of Private Value-Added, United States, 1950-2010

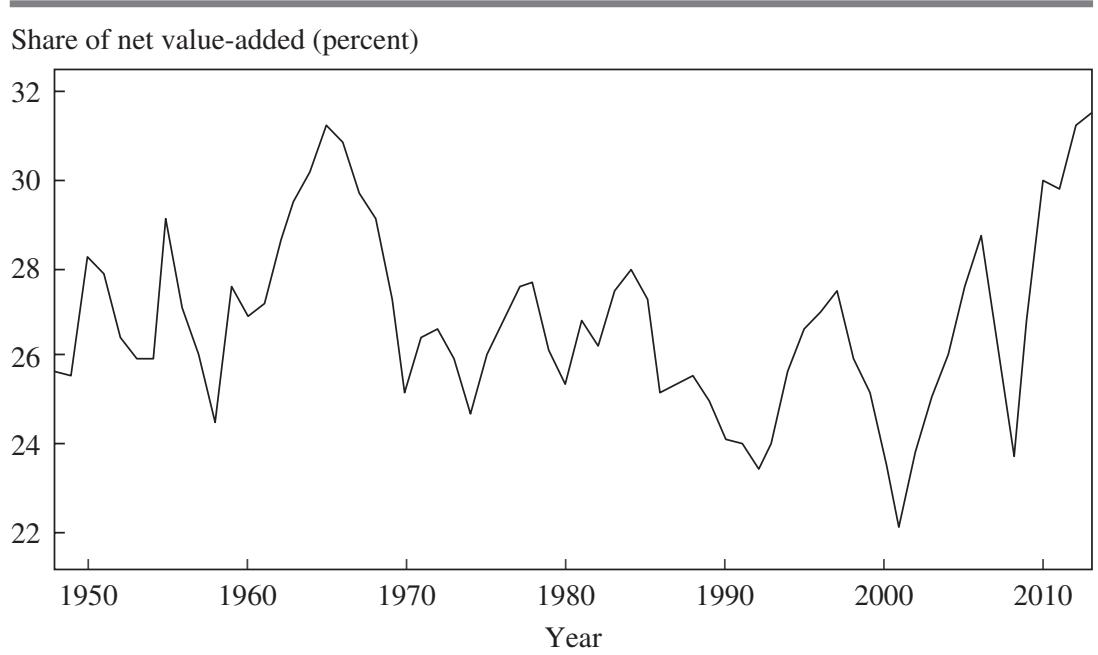

Source: National Income and Product Accounts.

Figure 11. Decomposition of Net Capital Share of Private Domestic Value-Added, United States, 1950-2010

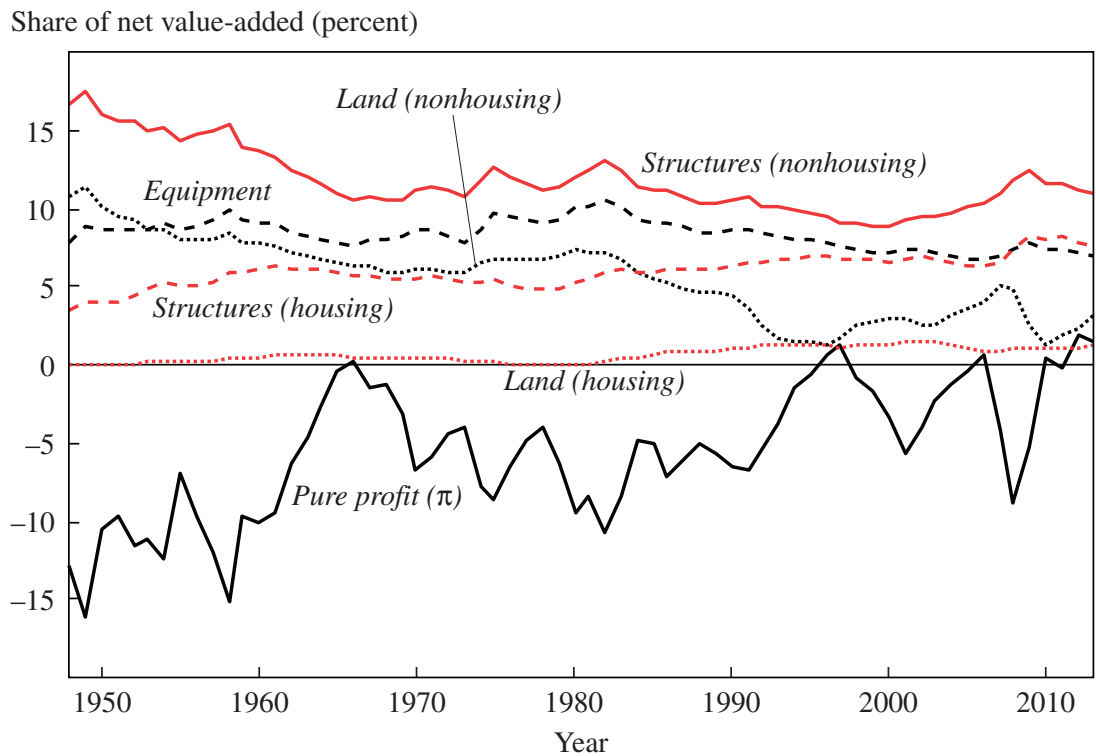

Source: Author's calculations based on National Income and Product Accounts, Financial Accounts of the United States. 
Another interesting feature of figure 11 is that there has been a sizable decline in the role of capital income from nonresidential land over time, from roughly 10 percent of net private value-added in the first half of the sample to an (erratic) average of roughly 2.5 percent today. In other words, there has been a shift in net capital income from nonresidential to residential land - but the decline in the former has been far larger than the growth in the latter, suggesting that the direct contribution of land to net capital income in the United States has actually fallen.

\section{Capital Share Theory: One-Sector Model}

In this section I study the canonical one-sector model of income shares and identify a key distinction between gross and net elasticities of substitution. I start by assuming that there is only one good, and then expand to a twogood model where the relative price of consumption and investment goods can vary.

\section{III.A. One-Sector, One-Good Model}

I now take a step back from the decomposition in section II-with its multiple capital goods - to recount the simplest, most traditional model of income shares, one with a single production sector and a single good. This offers a first-pass test of the theoretical viability of the accumulation view. All else equal, should we expect a larger capital-income ratio to cause an increase or decrease in capital's share?

Let $F(K, N)$ be a constant returns to scale production function, with capital $K$ and labor $N$ as factor inputs, and positive but diminishing returns in each factor. Assume that this is a one-good model, where the relative price of capital and output is fixed at one. The elasticity of substitution $\sigma$ between $K$ and $N$ is defined as

$$
\sigma \equiv-\left\{\frac{d\left[\log \left(F_{K} / F_{N}\right)\right]}{d[\log (K / N)]}\right\}^{-1} .
$$

This gives us the (inverse) elasticity of the ratio $F_{K} / F_{N}$ of marginal products to the ratio $K / N$ of capital. Equivalently, $\sigma$ tells us the extent to which a cost-minimizing producer's relative demand for $K / N$ will change if there is a change in the relative cost of using capital and labor as inputs. 
From the definition in equation 7, one can show that $\sigma$ also gives the inverse elasticity of $F_{K}$ with respect to a change in the capital-output ratio $K / F$ :

$$
\sigma=-\left\{\frac{d\left(\log F_{K}\right)}{d[\log (K / F)]}\right\}^{-1},
$$

which implies that the elasticity of the capital income share $F_{K} K / F$ with respect to the capital-output ratio $K / F$ is

$$
\frac{d\left[\log \left(F_{K} K / F\right)\right]}{d[\log (K / F)]}=1-\frac{1}{\sigma} .
$$

This indicates the critical importance of the threshold $\sigma=1$. If $\sigma>1$, the elasticity is positive, so the capital income share will increase as $K / F$ rises. Inversely, if $\sigma<1$, the capital income share will fall as $K / F$ rises. In the important special case $\sigma=1$, diminishing returns exactly offset the increased quantity of capital, and the share remains constant.

Indeed, one of the original motivations behind Charles Cobb and Paul Douglas's (1928) eponymous production function was the apparent constancy of capital and labor shares in the data; this is guaranteed by the Cobb-Douglas production function $F(K, N)=K^{\alpha} N^{1-\alpha}$, which has a constant elasticity of substitution $\sigma=1$.

NET VERSUS GROSS Thus far, I have been ambiguous about whether the function $F$ gives gross production, or production net of depreciation. In principle, either interpretation is legitimate - especially since this is a onegood model, where the relative price of capital and output is fixed at one, and losses from capital depreciation can reasonably be included as part of the production function.

If $F$ is gross production, then $1-1 / \sigma$ is the elasticity of gross capital income with respect to the ratio of capital to gross output. If $F$ is net production, then $1-1 / \sigma$ is the elasticity of net capital income with respect to the ratio of capital to net output. As discussed in section I.A, both measures are useful, but net concepts are probably more meaningful when studying income distribution.

It is important to recognize that $\sigma$ depends greatly on which measure is used-a subtlety that is often overlooked. Suppose $F(K, N)$ is the gross 
production function, with an elasticity of substitution of $\sigma$. Then the net production function is $\tilde{F}(K, N)=F(K, N)-\delta K$, and from equation 8 the elasticity of substitution for $F$ is

$$
\begin{aligned}
\sigma & =\frac{d[\log (\tilde{F} / K)]}{d\left(\log \tilde{F}_{K}\right)} \\
& =\frac{d(F / K-\delta) /(F / K-\delta)}{d\left(F_{K}-\delta\right) /\left(F_{K}-\delta\right)} \\
& =\frac{d(F / K) /(F / K)}{d\left(F_{K}\right) /\left(F_{K}\right)} \times \frac{\left(F_{K}-\delta\right) /(F-\delta K)}{F_{K} / F} \\
& =\sigma \times \frac{\left(F_{K} K-\delta K\right) /(F-\delta K)}{F_{K} K / F} .
\end{aligned}
$$

Hence the elasticity of substitution $\tilde{\sigma}$ for the net production function ("net elasticity") equals the elasticity of substitution $\sigma$ for the gross production function ("gross elasticity") times the ratio of the net capital share $\left(F_{K} K-\delta K\right) /(F-\delta K)$ and the gross capital share $F_{K} K / F$. Since the net capital share is always less than the gross capital share, it follows that the net elasticity is always below the gross elasticity.

Why, intuitively, is the net elasticity always lower? The net return on capital $\tilde{F}_{K}$ is less than the gross return $F_{K}$ by a constant-the depreciation rate $\delta$-meaning that a given change in $F_{K}$ translates into an equal absolute-and a larger relative-change in $\tilde{F}_{K}$. For instance, if $\delta=5$ percent, and $F_{K}$ declines from 10 to 8 percent, $\tilde{F}_{K}$ will decline from 5 to 3 percent. A 20 percent decline in the gross return becomes a 40 percent decline in the net return, and the ratio of the two is (A). As we increase capital relative to labor, the net marginal product of capital declines more rapidly than the gross-in short, capital is less substitutable for labor from a net perspective.

CALIBRATING To obtain an illustrative calibration, I take the data from section II.C, where pure profits are estimated using the quadratic path for $r(t)$. I exclude pure profits and land from the capital share, since they are not reproducible forms of capital and the relevant question for the Piketty (2014) hypothesis is whether adding more reproducible capital through investment increases or decreases capital's share of income. 
In the most recent year in the sample, 2013, the resulting U.S. private net capital share (excluding pure profits and land) was 25.6 percent, while the U.S. private gross capital share (excluding pure profits and land) was 34.5 percent. This results in a ratio of approximately 0.74 , and equation 10 implies

$$
\tilde{\sigma} \approx 0.74 \times \sigma,
$$

so that the net elasticity is slightly less than three-quarters of the gross elasticity.

If the decomposition in section II.C is performed assuming a lower rate of return $r$, such that a more significant share of net capital income is attributed to pure profits rather than returns on measured capital, then the ratio can be appreciably lower than in equation 11 . For instance, in an alternative estimate where $r$ is chosen to be roughly 5.5 percent for the corporate sector-implying that half of long-run net capital income is attributable to pure profits - the private net and gross capital shares (excluding pure profits and land) become 15.5 percent and 25.6 percent, respectively, resulting in a ratio of approximately 0.60 .

EMPIRICAL IMPLICATIONS Ever since Kenneth Arrow and others (1961) first proposed the constant elasticity of substitution (CES) production function, researchers have attempted to estimate the key elasticity parameter. These studies have almost always looked at the elasticity of substitution in the gross production function.

The literature is vast and its conclusions are muddled, but one consistent theme has been the rarity of high elasticity estimates. Chirinko (2008) provides an excellent summary of the empirical literature, listing estimates from many different sources and empirical strategies. Table 3 displays the estimates compiled there, both in their original gross terms and converted to net terms, where the conversion factor of 0.74 from equation 11 is used.

Of the 31 sources listed, table 3 reveals that only five sources show a gross elasticity above 1 , and only two imply a net elasticity above $1 .{ }^{24}$ From equation 9 it follows that a rise in the capital-income ratio, holding the production function constant, most likely will cause a decline in the net share of capital income. This is inconsistent with the Piketty (2014) and Piketty

24. For a few sources that list a range of elasticities, I take the midpoint. This has minimal effect on the distribution. 
Table 3. Distribution of Chirinko Elasticity Estimates in Gross and Net Terms ${ }^{a}$

\begin{tabular}{lccccc}
\hline & {$[0,0.5)$} & {$[0.5,1)$} & {$[1,1.5)$} & {$[1.5,2)$} & {$[2,4)$} \\
\hline Frequency of gross sigma & 14 & 12 & 3 & 1 & 1 \\
Frequency of net sigma & 21 & 8 & 1 & 0 & 1 \\
\hline
\end{tabular}

a. Based on estimates compiled by Chirinko (2008); gross terms as originally stated, and net terms converted using equation 11 .

and Zucman (2014) versions of the accumulation view, which hold that a rise in the capital-income ratio has led—and will continue to lead—-to a rise in capital's net share.

IMPLICATIONS FOR $r-g$ A closely related theme in Piketty (2014) is the gap $r-g$ between the real return $r$ on capital and the real growth rate $g$ of the economy. This gap, for instance, gives the rate at which a wealthy dynasty can withdraw capital income for consumption purposes without decreasing its wealth relative to the size of the economy. More generally, when $r-g$ is higher, "old" accumulations of wealth become more important relative to "new" ones. Higher $r-g$ generally implies that the power-law tail of the wealth distribution has a smaller exponent-so that there is more inequality of wealth at the top, and extreme levels are more likely. Many readers take the dynamics of $r-g$ to be the central theme of Piketty's 2014 book.

Both Piketty (2014) and Piketty and Zucman (2014) make heavy use of the identity

$$
\frac{K}{Y^{\text {net }}}=\frac{s}{g},
$$

dubbed the "Second Fundamental Law of Capitalism," where $s$ is the net savings rate and $g$ is the growth rate. This identity only holds asymptotically - if $s$ or $g$ changes, convergence to the new value of $K / Y^{\text {net }}$ does not happen instantaneously-and it is unlikely that $s$ is exogenous and invariant to changes in $g$. Nevertheless, Piketty (2014) argues that it is useful to explore the implications of this identity given exogenous $s$, particularly the fact that $K / Y^{n e t}$ rises as $g$ falls, which is central to the projection that the capital-income ratio will rise in the future. ${ }^{25}$

25. There is some conflict between the assumption of exogenous $s$ for all income and the emphasis on $r-g$. If only this fraction $s$ of capital income $r$ is saved, then existing fortunes will grow at the rate $s \cdot r-g$, not $r-g$; and for plausible values of $s$ as a share of all income, $s \cdot r-g$ is likely to be quite negative, implying the rapid erosion of existing wealth. 
If $r=F_{K}$, then equation 8 shows that the elasticity of $r$ with respect to $K / Y^{n e t}$ is simply $-\tilde{\sigma}^{-1}$, where $\tilde{\sigma}$ is the net elasticity of substitution. For exogenous $s$, equation 12 indicates that the elasticity of $K / Y^{\text {net }}$ with respect to $g$ is -1 , implying that the elasticity of $r$ with respect to $g$ is $\tilde{\sigma}^{-1}$. It follows that

$$
\frac{\partial(r-g)}{\partial g}=\frac{r}{g} \tilde{\boldsymbol{\sigma}}^{-1}-1
$$

This expression is positive if $r / g>\tilde{\sigma}$. Again taking data from section II.B, in 2013 the average return on measured capital was 7.5 percent. Taking this to be the $r$ in equation 13, and taking $g$ to be 2.5 percent (approximate trend real GDP growth in the United States in the last 25 years), we have $r / g=3$, in which case the derivative in equation 13 is positive as long as the net elasticity $\tilde{\sigma}$ is less than 3 .

The evidence in table 3 indicates that this is overwhelmingly likely. Indeed, converting by equation 11, a net elasticity of 3 corresponds to a gross elasticity of $\sigma=\tilde{\sigma} / 0.74=4.05$, which is above every estimate listed in Chirinko (2008) and above virtually every estimate in the wider literature. Consequently, a decline in $g$ will result in a decline in $r-g$ : the decline in $g$ itself is less than the decline in $r$ that it induces through capital accumulation and diminishing returns. Given the assumption (equation 12) on capital accumulation, the prediction in Piketty (2014) that $r-g$ will rise as $g$ falls is especially hard to reconcile with empirically plausible degrees of substitutability.

\section{III.B. One-Sector, Two-Good Model}

The canonical model in section III.A can be enriched slightly by allowing the price $P_{K}$ of capital relative to the output good to vary. This modification is central to the account in Karabarbounis and Neiman (2014a), who attribute the rise in the gross capital share to high capital demand induced by a fall in $P_{K}$.

To be more explicit, take the net required return $r$ on capital as given. Ignoring expected capital gains, demand for capital is pinned down by the condition

$$
F_{K}(K, N)=P_{K}(r+\delta)
$$


The elasticity of the gross capital/output ratio $K / F$ with respect to $P_{K}$ is then

$$
\frac{\partial[\log (K / F)]}{\partial\left(\log P_{K}\right)}=\frac{d[\log (K / F)]}{d\left(\log F_{K}\right)} \times \frac{\partial\left(\log F_{K}\right)}{\partial\left(\log P_{K}\right)}=-\sigma
$$

where $\partial\left(\log F_{K}\right) / \partial\left(\log P_{K}\right)=1$ follows directly from equation 14 , and $d(\log (K / F)) / d\left(\log F_{K}\right)=-\sigma$ follows from equation 8 . The elasticity of the gross capital share with respect to $P_{K}$ becomes

$$
\frac{\partial\left[\log \left(F_{K} K / F\right)\right]}{\partial\left(\log P_{K}\right)}=\left\{1+\frac{d[\log (K / F)]}{d\left(\log F_{K}\right)}\right\} \times \frac{\partial\left(\log F_{K}\right)}{\partial\left(\log P_{K}\right)}=1-\sigma,
$$

implying that a decline in the relative price $P_{K}$ of capital will increase the gross capital share if $\sigma>1$.

Meanwhile, the elasticity of the net capital share with respect to $P_{K}$ can be obtained through a somewhat more involved computation. The result, first derived by Karabarbounis and Neiman (2014b), is

$$
\frac{\partial\left\{\log \left[\left(F_{K}-\delta P_{K}\right) K /\left(F-\delta P_{K} K\right)\right]\right\}}{\partial\left(\log P_{K}\right)}=(1-\sigma) \times \frac{F}{F-\delta P_{K} K} .
$$

Note that $\sigma=1$ is still the critical threshold: a decline in the relative price $P_{K}$ of capital increases both the net and gross capital shares if $\sigma>1$. This consistency is a noteworthy contrast with the distinction (equation 10) between gross and net elasticities of substitution, where a rise in the capital-output ratio could produce an increase in the gross capital share and a decrease in the net capital share. From an intuitive standpoint, this is unsurprising: since we are holding $r$ constant, the ratio $r /(r+\delta)$ of net to gross capital income is fixed, and the two move in the same direction in response to a change in $P_{K}$.

Karabarbounis and Neiman (2014b) stress the role of equation 17, which shows that their focus on the role of changes in $P_{K}$ can potentially account for simultaneous changes in both the gross and the net capital shares, assuming that the gross elasticity of substitution $\sigma$ is greater than 1 . In light of the estimates compiled in table 3 (26 out of 31 of which find 
$\sigma<1), \sigma>1$ still appears unlikely, but it is somewhat more plausible than $\tilde{\sigma}>1$.

\section{Capital Share Theory: A Multisector Model}

In this section I expand beyond the one-sector model, constructing a tentative multisector model that allows a more nuanced analysis, including consideration of the housing sector. I then subject this model to four exogenous shocks, namely the required rate of return, the price of equipment investment, the price of residential structures investment, and the quantity of residential land.

\section{IV.A. Design of the Multisector Model}

The theory in section III enables a first-pass analysis of how the distribution of income is affected by various forces. It shows that accumulation of capital, all else equal, will likely result in a decline in the net capital share, since the net elasticity of substitution is almost certainly below 1 . This counters the central hypothesis of Piketty (2014). It also shows that a decline in the relative price $P_{K}$ of capital, holding the required return $r$ constant, will result in an increase in the net capital share if the gross elasticity of substitution is above 1 -a claim that is still hard to reconcile with the bulk of empirical evidence, but for which Karabarbounis and Neiman (2014a) mount a spirited case.

Nevertheless, the one-sector model in section III is in many ways unsatisfactory as a model of the distribution between capital and labor. For instance, sections I and II demonstrated the decisive role of the housing sector in the long-term trajectory of the net capital share-but a one-sector model is by construction unable to account for a shift toward housing. Indeed, Piketty (2015) has recently voiced discomfort with the one-sector interpretation of the rising capital share, arguing that "the right model to think about rising capital-income ratios and capital shares in recent decades is a multisector model of capital accumulation" (p. 81). In this section I will construct a tentative version of such a model.

NESTED FRAMEWORK Given the central role of housing in sections I and II, it is first important to distinguish between nonhousing and housing output. If household preferences are homothetic in these two types of output, the household objective can be written as a monotonic transformation of a constant-returns-to-scale aggregator $Z\left(Y_{n h}, Y_{h}\right)$ that takes nonhousing and housing services as inputs. We can view $Z$ as the "top-level" production function for the economy. 
For the nonhousing sector, it will be useful to model the production process in a way that reflects the different types of capital studied in section II (equipment, structures, and land), so that the results from that disaggregation exercise can be used to inform the model. One natural approach is to assume that structures and land together provide "real estate" services that serve as an input to production, while labor and equipment together provide all other services. This approach enables me to draw upon several empirical literatures, which estimate the relevant elasticities of substitution-for instance, the elasticity of substitution between structures and land in the production of real estate services, or the elasticity of substitution between housing and nonhousing in consumer preferences.

Concretely, let $H\left(N, K_{e}\right)$ be a constant-returns-to-scale aggregator combining labor $N$ and equipment $K_{e}$, and let $G_{1}\left(K_{s 1}, L_{1}\right)$ be another constantreturns-to-scale aggregator combining nonresidential structures $K_{s 1}$ and land $L_{1}$. Finally, let $F$ be another constant-returns-to-scale aggregator that combines $H$ and $G_{1}$, so that the consolidated production function for the nonhousing sector takes the form

$$
Y_{n h}=F\left[H\left(N, K_{e}\right), G_{1}\left(K_{s 1}, L_{1}\right)\right] .
$$

Following section II, I assume that gross output in the nonhousing sector is sold at some markup $\mu$ over marginal cost.

Similarly, suppose that residential structures $K_{s 2}$ and land $L_{2}$ are combined by an aggregate $G_{2}\left(K_{s 2}, L_{2}\right)$ to provide housing services, so that the production function for the housing sector takes the form

$$
Y_{h}=G_{2}\left(K_{s 2}, L_{2}\right) .
$$

Finally, as already mentioned, $Z$ combines $Y_{n h}$ and $Y_{h}$ into an aggregate that reflects household preferences:

$$
Y=Z\left(Y_{n h}, Y_{h}\right)
$$

This multisector economy captures the distinction between the nonhousing and housing sectors, as well as all five forms of capital analyzed in section II: equipment $\left(K_{e}\right)$, nonresidential structures $\left(K_{s 1}\right)$, nonresidential land $\left(L_{1}\right)$, residential structures $\left(K_{s 2}\right)$, and residential land $\left(L_{2}\right)$. 
The aggregate, nested structure of production in the economy is depicted in the tree below.

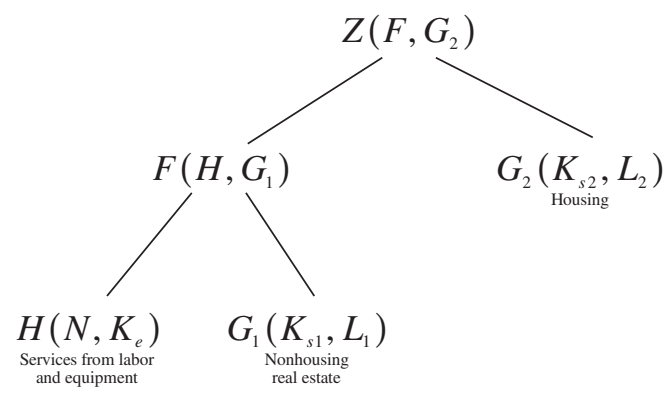

ELASTICITIES OF SUBSTITUTION The response of the multisector model to various shocks is influenced by the local (gross) elasticities of substitution $\left(\sigma_{Z}, \sigma_{F}, \sigma_{G_{1}}, \sigma_{G_{2}}, \sigma_{H}\right)$ for each of the five constant-returns-to-scale production functions $\left(Z, F, G_{1}, G_{2}, H\right)$ in the model above.

Although there are extensive empirical literatures that study many of these elasticities, a convincing research design is often elusive, and there is rarely strong consensus around a single point estimate. In the absence of such consensus, I will draw upon each literature to obtain plausible ranges for each elasticity, and study the implications of choosing different values within each range. The objective is to see which conclusions, if any, emerge robustly from the multisector model despite allowing for some uncertainty about the $\sigma s$. Another goal is to investigate which $\sigma$ s matter most to aggregate outcomes, both to clarify thinking and to direct future research toward the most crucial targets.

Surveying the relevant literatures, I find the following.

First, $\sigma_{z}$ equals the elasticity of demand for housing services (as a share of total output) with respect to its price (relative to the aggregate price index for Z). Closely related elasticities of demand for housing have been studied in the literature, which has generally obtained relatively low values. For instance, in a review of the literature, John Ermisch, Jeanette Findlay, and Kenneth Gibb (1996, p. 67) state that "price elasticity estimates are less dispersed than the income elasticity measures, yielding results between 0.5 and 0.8 " and they themselves provide an estimate of $0.4 .{ }^{26} \mathrm{I}$ set a range of $\sigma_{z} \in[0.4,0.8]$.

26. $\sigma_{Z}<1$ is strongly supported by casual observation as well. For instance, as the real price of housing services has risen in the United States over the last several decades, its share of consumption has increased slightly; there is also a well-known tendency for consumers to spend a larger share of their budgets on housing in areas where housing is expensive. 
Second, $\sigma_{F}$, the elasticity of substitution between real estate and other services in the nonhousing sector, does not map closely onto any empirically studied elasticity. In the absence of direct evidence, I set a wide range of $\sigma_{F} \in[0.5,1.5]$.

Third, $\sigma_{G_{1}}$ and $\sigma_{G_{2}}$ are the elasticities of substitution between structures and land in the nonhousing and housing sectors, respectively. These elasticities play an important role in the urban economics literature, where substitutability between structures and land in the provision of real estate services is of great practical and theoretical interest.

The more voluminous literature is for housing, $\sigma_{G_{2}}$, with a widely cited early entry by Richard Muth (1971), who estimates $\sigma_{G_{2}}=0.5$ using several approaches. More recently, Paul Thorsnes (1997) surveys the literature and finds that recent estimates have generally been below 1 , in the range of $[0.5,1]$; but he also argues that some of these estimates may be biased downward due to measurement error and that the true elasticity may not be much below 1. This claim is seconded by Gabriel Ahlfeldt and Daniel McMillen (2014). In light of these findings, I set a range of $\sigma_{G_{2}} \in[0.5,1]$.

The literature for nonhousing real estate, $\sigma_{G_{1}}$, is more scattered, with a range of elasticity estimates similar to that for housing — generally below one, but with concerns about bias from measurement error. For instance, John Clapp (1979) obtains elasticities from high-rise office data mostly in the range of $[0.5,0.75]$, but in a tentative attempt to correct for measurement error finds that elasticities closer to 1 may be appropriate. Interpretation is complicated by the fact that nonhousing real estate is much more heterogeneous than housing real estate, spanning everything from high-rise office towers to farmland. Amid this uncertainty, I set the range $\sigma_{G_{1}} \in[0.5,1]$.

Fourth, $\sigma_{H}$ is the elasticity of substitution between equipment and labor. This is of great speculative interest - there are frequent discussions about the extent to which automation, for instance, can replace existing workers, and $\sigma_{H}$ governs the extent to which the decline in equipment prices documented by Karabarbounis and Neiman (2014a) will lead to substitution away from labor. In his survey, Chirinko (2008) reports a wide range of relevant estimates; the majority are still below 1, but several are above 1 as well, and he suggests that the elasticity for equipment may be higher than the aggregate elasticity. For instance, Cummins and Hassett (1992) obtain implied elasticities of 0.93 for equipment but only 0.28 for structures, and the estimates listed by Chirinko (2008) that use computer investment obtain values as high as 1.58 . I therefore set a range $\sigma_{H} \in[0.5,1.5]$. 


\section{IV.B. Response of the Net Capital Share to Exogenous Shocks}

I now study the elasticity of the net capital share with respect to various shocks in the multisector model, whose structure was described in the previous section.

GENERAL METHODOLOGY I assume that the quantities $\left(N, L_{1}, L_{2}\right)$ of labor and both types of land are exogenous. I take final output from $Z$ to be the numeraire, and assume that the prices $P_{e}, P_{s 1}$, and $P_{s 2}$ of reproducible capital in terms of this numeraire are exogenously fixed by technology. ${ }^{27}$ As in equation 2 , the user cost of reproducible capital for $i \in\left\{e, s_{1}, s_{2}\right\}$ is

$$
W_{K_{i}}=P_{i}\left(r+\delta-g_{P_{i}}\right),
$$

where the required return $r$, the depreciation rate $\delta$, and the expected real change in prices $g_{P_{i}}$ are also all assumed to be exogenous. As in section II, $r$ may differ between the nonhousing and housing sectors. The quantities $\left(K_{e}, K_{s 1}, K_{s 2}\right)$ of reproducible capital are then given endogenously by demand at this user cost.

I will consider exogenous shocks to either the quantities $\left(N, L_{1}, L_{2}\right)$, the prices $\left(P_{e}, P_{s 1}, P_{s 2}\right)$, or $r$, which jointly determine the user costs $\left(W_{K_{e}}\right.$, $W_{K_{51}}, W_{K_{s_{2}}}$. The elasticity of factor shares in the model with respect to either of these shocks depends only on the initial gross and net shares and the local elasticities of substitution $\left(\sigma_{Z}, \sigma_{F}, \sigma_{G_{1}}, \sigma_{G_{2}}, \sigma_{H}\right)$ at each level of production; with these in hand, it can be obtained numerically. (Unfortunately, unlike in Oberfield and Raval (2014), elasticities here cannot be expressed in closed form as a weighted average of the individual elasticities $\left(\sigma_{Z}, \sigma_{F}, \sigma_{G_{1}}, \sigma_{G_{2}}, \sigma_{H}\right)$. Analytically, this is due to the fact that I assume more than one exogenous quantity.)

I calibrate the initial shares to match the decomposition of the U.S. economy in section II.C for the final year in the sample, 2013. Table 4 displays the resulting gross and net shares of each factor as a fraction of total income, while table 5 shows the gross shares of each factor as a fraction of the parent aggregate.

27. Since housing is probably not an input to the production of equipment or structures, it would be slightly more natural to assume that these prices are fixed relative to the price of nonhousing output $F$; I assume they are fixed relative to $Z$ for convenience, and in general the relative prices of $F$ and $Z$ do not change enough that this has a sizable impact on the results. 
Table 4. Gross and Net Shares of Factors and Higher-Level Aggregates Used to Calibrate the Multisector Model ${ }^{a}$ (Percent)

\begin{tabular}{lcc} 
& Gross aggregate share & Net aggregate share \\
\hline Labor $(N)$ & 60 & 68 \\
Equipment $\left(K_{e}\right)$ & 12 & 7 \\
Nonresidential structures $\left(K_{s 1}\right)$ & 12 & 11 \\
Nonresidential land $\left(L_{1}\right)$ & 3 & 3 \\
Residential structures $\left(K_{s 2}\right)$ & 10 & 8 \\
Residential land $\left(L_{2}\right)$ & 1 & 1 \\
Pure capital profits $(\pi)$ & 1 & 2 \\
Nonhousing production, other $(H)$ & 72 & 76 \\
Nonhousing production, real estate $\left(G_{1}\right)$ & 15 & 14 \\
Housing production, real estate $\left(G_{2}\right)$ & 11 & 9 \\
Nonhousing production, total $(F)$ & 88 & 90
\end{tabular}

Source: Author's calculations; see text for details.

a. Factors and aggregates taken from the 2013 decomposition presented in section II.C of this paper.

IMPLEMENTATION AND RESULTS I focus on the elasticity of the net capital share with respect to four specific exogenous shocks:

- A shock to the required rate of return $r$

- A shock to the price of equipment investment $P_{e}$

- A shock to the price of residential structures investment $P_{s 2}$, and

- A shock to the quantity of residential land $L_{2}$.

As discussed in greater detail below, the first and second correspond to the Piketty (2014) and Karabarbounis and Neiman (2014a) versions of the accumulation view, respectively. The third and fourth shocks, which

Table 5. Gross Shares of Production Within Each Higher-Level Aggregate Used to Calibrate the Multisector Modela (Percent)

\begin{tabular}{llc}
\hline & & $\begin{array}{c}\text { Gross } \\
\text { share }\end{array}$ \\
\hline Nonhousing production, other $(H)$ & Labor $(N)$ & 83 \\
& Equipment $\left(K_{e}\right)$ & 17 \\
Nonhousing production, real & Nonresidential structures $\left(K_{s 1}\right)$ & 82 \\
estate $\left(G_{1}\right)$ & Nonresidential land $\left(L_{1}\right)$ & 18 \\
Housing production, real estate $\left(G_{2}\right)$ & Residential structures $\left(K_{s 2}\right)$ & 90 \\
& Residential land $\left(L_{2}\right)$ & 10 \\
Nonhousing production, total $(F)$ & Nonhousing production, other $(H)$ & 83 \\
& Nonhousing production, real estate $\left(G_{1}\right)$ & 17 \\
Total production $(Z)$ & Nonhousing production, total $(F)$ & 89 \\
& Housing production, real estate $\left(G_{2}\right)$ & 11
\end{tabular}

Source: Author's calculations; see text for details.

a. Based on shares presented in table 4 . 
Table 6. Minimum and Maximum Elasticities of Net Capital Share with Respect to Shocks ${ }^{\mathrm{a}}$

\begin{tabular}{lrcc}
\hline Shock & Min & Max & Benchmark \\
\hline Real interest rate $(r)$ & 0.04 & 0.54 & 0.26 \\
Price of equipment investment $\left(P_{e}\right)$ & -0.18 & 0.15 & 0.00 \\
Price of residential structures investment $\left(P_{s 2}\right)$ & 0.00 & 0.16 & 0.07 \\
Quantity of residential land $\left(L_{2}\right)$ & -0.04 & 0.00 & -0.01 \\
\hline
\end{tabular}

Source: Author's calculations; see text for details.

a. Elasticities for choices of $\sigma_{i}$ within range.

relate to residential housing, correspond to my proposed alternative of a "scarcity view."

The core results are summarized in tables 6,7 , and 8 . For table 6, I calculate the elasticity of the net capital share with respect to each shock over the full range of $\sigma_{i}$ deemed plausible in the previous section

$$
\begin{gathered}
(0.4,0.5,0.5,0.5,0.5) \leq\left(\sigma_{z}, \sigma_{F}, \sigma_{G_{1}}, \sigma_{G_{2}}, \sigma_{H}\right) \\
\leq(0.8,1.5,1.0,1.0,1.5)
\end{gathered}
$$

and report the minimum and maximum elasticities of the net capital share obtained for any combination of $\sigma_{i}$ in this range. I also calculate the elasticity of the net capital share at a set of "benchmark" $\sigma_{i}$, which I choose to be the midpoint of this range: $\left(\sigma_{Z}, \sigma_{F}, \sigma_{G_{1}}, \sigma_{G_{2}}, \sigma_{H}\right)=(0.6,1.0,0.75,0.75,1.0)$.

Table 7 provides additional insight into how different assumptions on $\sigma_{i}$ combine to produce an aggregate response to shocks. For each shock, the table shows the sensitivity (partial derivative) of the net capital share

Table 7. Sensitivity of the Elasticity of Net Capital Share to Changes in Each $\sigma_{i}$, Starting at Benchmark Values

\begin{tabular}{lccccc}
\hline & \multicolumn{5}{c}{ Sensitivity } \\
\cline { 2 - 6 } Shock & sigma_z & sigma_F & sigma_G1 & sigma_G2 & sigma_H \\
\hline Real interest rate $(r)$ & -0.21 & -0.21 & 0.03 & -0.01 & -0.19 \\
$\begin{array}{l}\text { Price of equipment } \\
\quad \text { investment }\left(P_{e}\right)\end{array}$ & 0.02 & 0.01 & 0.00 & 0.01 & -0.29 \\
$\begin{array}{l}\text { Price of residential } \\
\quad \text { structures }\end{array}$ & -0.17 & -0.03 & 0.00 & 0.01 & -0.04 \\
$\quad$ investment $\left(P_{s 2}\right)$ & & & & & \\
Quantity of residential & 0.03 & 0.00 & 0.00 & 0.01 & 0.00 \\
$\quad$ land $\left(L_{2}\right)$ & & & & & \\
\hline
\end{tabular}

Source: Author's calculations; see text for details. 
elasticity to changes in each of the underlying $\sigma_{i}$, starting from the benchmark values. Essentially, table 7 shows the gradient of the values in the "benchmark" column of table 6 with respect to perturbations in the $\sigma_{i}$.

For instance, in the case of a shock to $P_{e}$, the second row of table 7 shows small sensitivities to all $\sigma_{i}$ except $\sigma_{H}$, for which the sensitivity is -0.29 . This means that if $\sigma_{H}$ is increased slightly from its benchmark value-say, from $\sigma_{H}=1.0$ to $\sigma_{H}=1.1$ - the elasticity of the net capital share with respect to $P_{e}$ will decline by 0.029 . The intuition in this case is straightforward: when $\sigma_{H}$ is higher, it is easier to replace equipment with labor in response to higher equipment prices, meaning that a rise in $P_{e}$ will result in a smaller increase in (or greater decline in) net capital income.

Finally, table 8 decomposes the elasticity of the net capital share, at the benchmark $\sigma_{i}$, into contributing changes in each source of capital income. Each row of table 8 sums to the elasticity for the corresponding shock in the "benchmark" column of table 6, with one exception: an extra row is included for a shock to $P_{e}$, showing the decomposition in the "high elasticity" case where each elasticity $\sigma_{i}$ is chosen to be at the maximum of the range. (This is because there is virtually no effect from the shock to $P_{e}$ at the benchmark $\sigma_{i}$.) For instance, for a shock to the price $P_{s 2}$ of residential structures investment, the contribution of residential structures $K_{s 2}$ is 0.09 , out of a total elasticity (from table 6) of 0.07 ; this means that when the cost of residential investment rises, more than 100 percent of the resulting increase in the net capital share is due to a rise in income from residential structures themselves. I now discuss and interpret the results for each shock.

SHOCK TO THE REQUIRED RATE OF RETURN " $r$ " This case tests the Piketty (2014) hypothesis that a rise in savings will push up the net capital share. In general equilibrium, increased savings influences capital income by pushing down the real interest rate; hence, to learn the sign of the effect of savings on the net capital share, it suffices to study the partial equilibrium effect of a change in the real interest rate.

Since the decomposition of the U.S. economy in section II.C allows $r$ in the nonhousing and housing sectors to be different, I define a "shock to $r$ " to be a parallel shift $d r$ in these two rates of return. I then define the elasticity of the net capital share with respect to this shock to be

$$
\frac{\partial(\text { net capital share }) /(\text { net capital share })}{\partial r / r^{\text {ave }}},
$$

where $r^{\text {ave }}$ is the average return on capital across the economy as a whole, including both the nonhousing and housing sectors. 


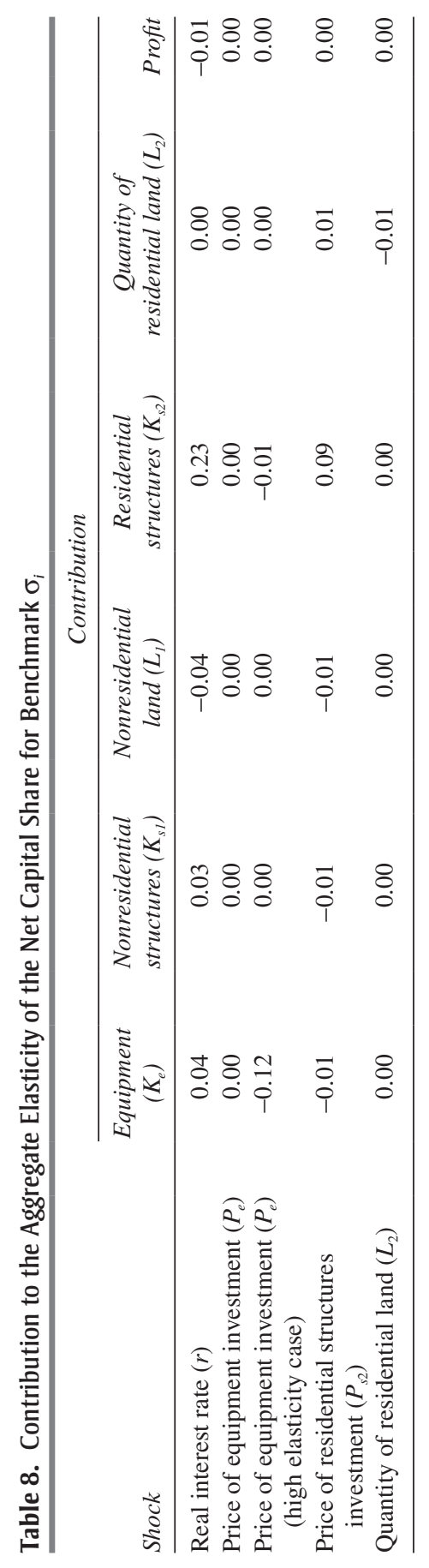


Table 6 shows that for all $\sigma_{i}$ within range (equation 21), the response of the net capital share to $r$ is positive-barely so at minimum (0.04) and strongly so at maximum (0.54). This is inconsistent with the Piketty (2014) hypothesis that a decline in $r$ can produce an increase in the net capital share, and it corroborates the findings from the single-sector model in section III.

Table 7 reveals that the response of the net capital share to $r$ depends primarily on three elasticities, all negatively: $\sigma_{Z}, \sigma_{F}$, and $\sigma_{H}$, each with a sensitivity of about -0.20 .

Each of these elasticities governs the extent to which an aggregate that includes labor (which is unaffected by $r$ ) can be substituted for an aggregate that does not include labor. But even when these elasticities are chosen at the maximum level in the range $\left(\sigma_{Z}=0.8, \sigma_{F}=1.5, \sigma_{H}=1.5\right)$, the response of the net capital share to $r$ remains slightly positive.

Table 8 shows that the vast majority of the response to $r$ comes from residential structures: at benchmark $\sigma_{i}$, a contribution of 0.23 out of an overall elasticity of 0.26 . This is for two reasons. First, since both housing $G_{2}$ and aggregate consumer demand $Z$ have $\sigma$ s below 1 , the direct positive impact of rising $r$ on income from residential structures outweighs the negative effect of substitution-much more so than for nonresidential structures or equipment. Second, since the analysis in section II.C finds a lower $r$ for the housing sector than the nonhousing sector, a parallel shift in these rates has a disproportionate effect on housing. This reinforces the centrality of housing to any assessment of the Piketty (2014) narrative.

Finally, table 8 indicates the importance of a crucial distinctionnamely, the distinction between (A) the ratio of housing capital to aggregate income and (B) the share of housing capital income in aggregate income. In response to rising $r$, (A) falls: higher $r$ pushes down the demand for residential structures relative to aggregate income, ${ }^{28}$ and since residential land's share of income remains roughly constant in table 8, higher $r$ will push down the valuation of this land relative to aggregate income. At the same time, as already discussed, (B) rises dramatically. Hence a shock to $r$ pushes (A) and (B) in different directions, making it important to document (A) and (B) separately.

28. This occurs in the model but is not directly visible in tables 6 through 8 . 
SHOCK TO THE PRICE OF EQUIPMENT INVESTMENT $P_{e}$ This case tests the Karabarbounis and Neiman (2014a) hypothesis that declining investment prices - which have been concentrated in equipment-will push up the net capital share. As table 6 shows, this remains ambiguous for the range of $\sigma_{i}$ specified in equation 21, which are consistent with either a positive or negative relationship between $P_{e}$ and the net capital share.

Table 7 makes clear the source of this ambiguity: the response of the net capital share to $P_{e}$ depends almost entirely on the elasticity of substitution $\sigma_{H}$ between labor and equipment. When $\sigma_{H}$ is near the top of the $[0.5,1.5]$ range, falling $P_{e}$ leads to a rise in the net capital share, consistent with Karabarbounis and Neiman $(2014 \mathrm{~b})$; when $\sigma_{H}$ is near the bottom, the opposite is true.

The "high elasticity" row in table 8, however, provides cause for skepticism regarding the Karabarbounis and Neiman (2014a) channel. Here, $P_{e}$ has a substantial negative effect on the net capital share. But this effect comes almost exclusively from the net capital income of equipment itselfwhich, in this partial equilibrium exercise, moves in parallel with the value of the equipment stock - rather than through some less direct channel. Section II found that the value of equipment (which has recently fallen) has followed a path quite distinct from the path of the net capital share (which has recently risen). This is not consistent with a major role for $P_{e}$.

For the $P_{e}$ hypothesis to be consistent with the data, it would be necessary for declining $P_{e}$ to push up the net capital share through some channel other than a rise in the value of the equipment stock. Karabarbounis and Neiman (2014b) sketch one such possibility, where falling $P_{e}$ can lead to an increase in the net capital share despite an actual decline in the aggregate value of equipment, but the multisector model here does not corroborate their mechanism. ${ }^{29}$

SHOCK TO THE PRICE OF RESIDENTIAL STRUCTURES INVESTMENT $\boldsymbol{P}_{s 2}$ In table 6 , a rise in $P_{s 2}$ leads to a rise in the net capital share for benchmark $\sigma_{i}$; for

29. Karabarbounis and Neiman (2014b) devise a model where two types of capital, highdepreciation (which can be interpreted as equipment) and low-depreciation (which can be interpreted as structures) combine to form a capital aggregate; the elasticity of substitution between these types of capital is less than 1, while the elasticity of substitution between the capital aggregate and labor is greater than 1. A decline in the price of equipment lowers the price of the capital aggregate, which induces substitution from labor to the capital aggregate; but since the elasticity of substitution between equipment and structures is less than 1 , this also causes a decline in equipment relative to structures. With the right parameters, it is possible for a decline in the price of equipment to increase the net capital share while net capital income from equipment itself actually declines. 
other choices of $\sigma_{i}$ within range (equation 21), there is at worst roughly no effect. According to table 7, the effect is most sensitive to the elasticity $\sigma_{Z}$ of substitution between housing and nonhousing output; and according to table 8 it works almost entirely through the net capital income of residential structures themselves. The mechanism here is relatively simple: when the ability to substitute away from housing is limited, costlier residential investment leads to a higher-value housing stock and a larger share of income accruing to housing.

SHOCK TO THE QUANTITY OF RESIDENTIAL LAND $L_{2}$ This is similar to the previous case. In table 6 , a decline in the quantity of residential land $L_{2}$ leads to a rise in the net capital share for benchmark $\sigma_{i}$; for other choices of $\sigma_{i}$ within range (equation 21), there is at worst roughly no effect. Again, according to table 7 , the effect is most sensitive to $\sigma_{z}$; now, however, the effect is smaller and works mainly through the net capital income earned by residential land.

SUMMARY OF RESULTS AND CONCLUSION I have examined the response of the multisector model to four exogenous shocks. The first two shocks correspond to versions of the accumulation view: a shock to $r$ captures the general equilibrium channel through which the rise in savings postulated by Piketty (2014) affects factor shares, while a shock to $P_{e}$ is central to the Karabarbounis and Neiman (2014a) narrative.

In both cases, the results do not support the proposed mechanism. For all choices of $\left\{\sigma_{i}\right\}$ within the range considered, a fall in $r$ leads to a fall in the net capital share, in contrast with Piketty (2014). Meanwhile, although a fall in $P_{e}$ can produce a rise in the net capital share, it only does so by pushing up the net capital income from equipment itself, which is at odds with the evidence from section II.

The latter two shocks both embody some form of the scarcity view, which is more successful in the multisector model. Either a rise in the price $P_{s 2}$ of residential investment or a fall in the quantity $L_{s 2}$ of residential land leads to a rise in the net capital share, for the vast majority of $\left\{\sigma_{i}\right\}$ in the range (equation 21). In both cases, the mechanism works by increasing the net capital income earned by housing, consistent with the dramatic rise in the contribution of housing documented in section I.

\section{IV.C. Counterfactual Exercise}

Building upon the promise of the scarcity view in the previous section, I now use the multisector model to perform a counterfactual exercise, exploring the implications of alternative paths for $P_{s 2}$ and $L_{s 2}$. 
The real price $P_{s 2}$ of residential investment has risen in the last several decades in the United States; furthermore, real output has grown substantially, putting pressure on the supply of residential land. I consider a counterfactual where these two forces are not present: where the real price of $P_{s 2}$ is instead constant from the beginning (1948) of the sample period onward, and where the quantity of residential land $L_{s 2}$ grows in tandem with real output from the beginning of the sample period onward. ${ }^{30}$

In contrast to the exercises in section IV.B, which consider only local shocks to exogenous variables, this counterfactual involves large global changes. It requires additional global assumptions to compute; for this purpose, I will assume that the production functions $\left(Z, F, G_{1}, G_{2}, H\right)$ each have a globally constant elasticity of substitution. I consider two choices of $\left\{\sigma_{i}\right\}$ : first, the benchmark $\left(\sigma_{Z}, \sigma_{F}, \sigma_{G_{1}}, \sigma_{G_{2}}, \sigma_{H}\right)=(0.6,1.0,0.75,0.75,1.0)$; and second, an alternative $\left(\sigma_{Z}, \sigma_{F}, \sigma_{G_{1}}, \sigma_{G_{2}}, \sigma_{H}\right)=(0.4,0.5,0.75,0.75,0.5)$ that sets $\sigma_{Z}, \sigma_{F}$, and $\sigma_{H}$ (the $\sigma \mathrm{s}$ that govern the response to $P_{s 2}$ and $L_{2}$, according to table 7) to the minimum values in the range (equation 21).

Figure 12 displays the results of this exercise, distinguishing between the housing and nonhousing components of the net capital share. Consistent with table 8 , there is little effect working through the nonhousing component. Furthermore, the large initial increase and then decline in the housing component, through 1980, is left untouched by the counterfactuals. However, much of the subsequent increase in the housing component is eroded.

This is consistent with a role for rising residential investment costs, along with growing scarcity of residential land, in driving up housing's contribution to the net capital share: when these forces are reversed in a counterfactual, we see less of a rise. At the same time, figure 12 makes clear the limitations of this account. It does not explain the fall and rise in the nonhousing component, nor can it explain all aspects of the housing time series. The scarcity view, therefore, is only a partial replacement for the accumulation view: it achieves better consistency with data and theory, but does not purport to explain more than a fragment of the evolving factor income distribution.

30. To make this modification, I assume that the quantity of land $L_{s 2}$ was in reality constant, and then expand it in each year by a fraction equal to cumulative real GDP growth since 1948. Depending on the interpretation of $L_{s 2}$, the assumption that it has been constant may or may not be appropriate. 
Figure 12. Counterfactual Paths for the Housing and Nonhousing Components of Net Capital Share, United States, 1950-2010a

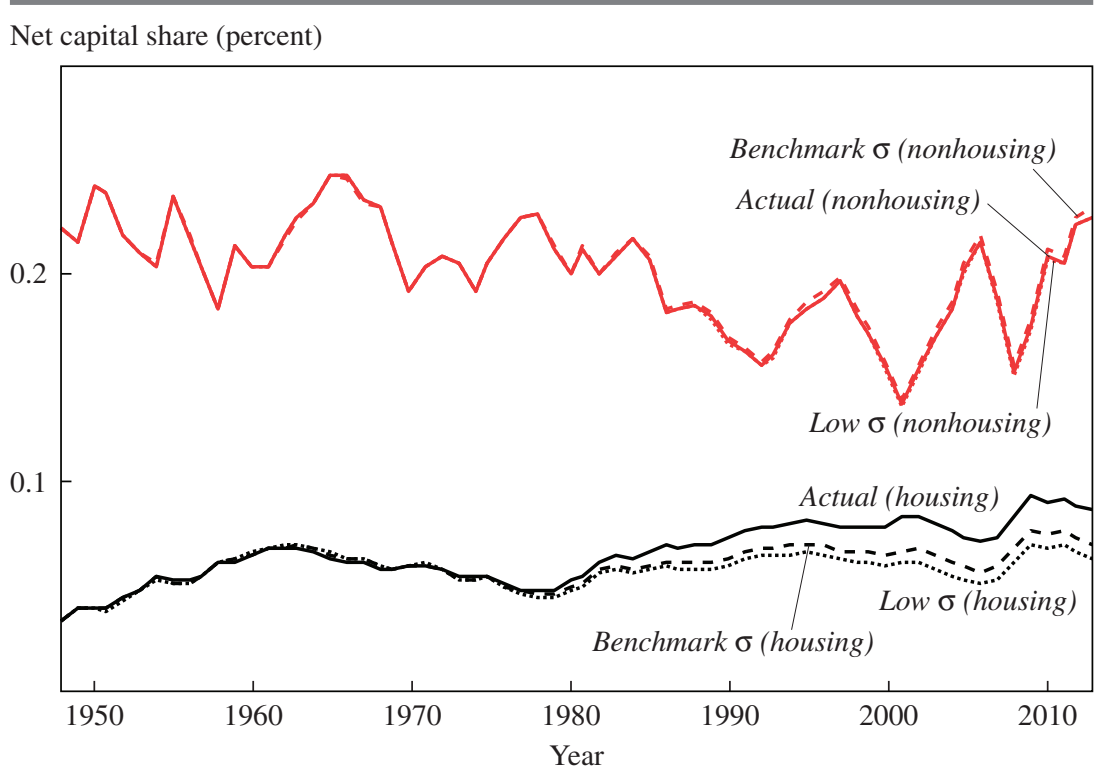

Source: Author's calculations; see text.

a. Assuming no change in the real price of residential structures investment and a constant ratio of the quantity of residential land to the quantity of real output.

\section{Conclusion}

The aging Kaldor (1957) facts have retreated in the face of experience. Today, macroeconomists no longer claim that factor shares are constantbut what should replace the old consensus?

It is increasingly commonplace to believe that labor is ceding ground to capital. But a closer look at postwar experience reveals a murkier story, in which steady increase is limited to the gross capital share. The net share, by contrast, has fallen and then recovered; it consists of a large long-term increase in net capital income from housing, and a more volatile contribution from the rest of the economy, with little cumulative movement in either direction.

Even more elusive than these facts is a cohesive explanation of them. The accumulation view, in both its Piketty (2014) and Karabarbounis and Neiman (2014a) variants, falters in multiple respects. It cannot explain the dominant role of housing, nor can it be readily reconciled with the evidence 
on elasticities of substitution. Outside of housing, there appears to be little correlation between the capital-income ratio and the net capital share.

By contrast, the rise in housing's contribution to the capital share can be explained in part as the result of scarcity. The rising real cost of residential investment and the limited quantity of residential land have conspired to make housing more expensive, and given low elasticities of substitution this has meant a rise in housing's share of income.

With these trends in mind, policymakers concerned about the distribution of income should keep an eye on housing costs. Many urban economists, including Glaeser, Gyourko, and Saks (2005) and Quigley and Raphael (2005), have documented explicitly how restrictions on land use and residential construction inflate the cost of housing. Outside of housing, however, this paper raises more questions than it answers about the evolution of the net capital share: once the accumulation view has been discarded, there is no master narrative at hand that can explain the postwar fall and rise.

If anything, these results suggest that concern about inequality should be shifted away from the overall split between capital and labor and toward other aspects of distribution, such as the within-labor distribution of income. Although the net capital share has at times seen dramatic shifts both up and down, away from housing its long-term movement has been quite small, and there is no compelling reason to suggest that this pattern will change going forward.

No doubt, however, the distribution between capital and labor will continue to be a salient issue: we surely have not seen the last of David Ricardo's "principal problem of Political Economy."

ACKNOWLEDGMENTS For their helpful comments and conversations I thank my discussants Robert Solow and Brad DeLong, the participants at the Spring 2015 Brookings Panel on Economic Activity, Adrien Auclert, Loukas Karabarbounis, Stephen Murphy, Thomas Piketty, Alp Simsek, Ludwig Straub, Ivan Werning, Gabriel Zucman, and the volume editors. 


\section{References}

Ahlfeldt, Gabriel M., and Daniel P. McMillen. 2014. "New Estimates of the Elasticity of Substitution of Land for Capital." In ERSA Conference Papers. Louvain-la-Neuve, Belgium: European Regional Science Association.

Andrews, Dan, and Aida Caldera Sánchez. 2011. "The Evolution of Homeownership Rates in Selected OECD Countries: Demographic and Public Policy Influences." OECD Journal: Economic Studies 1: 1-37.

Arpaia, Alfonso, Esther Pérez, and Karl Pichelmann. 2009. "Understanding Labour Income Share Dynamics in Europe." Economic Paper no. 379, European Commission, Brussels.

Arrow, K. J., H. B. Chenery, B. S. Minhas, and R. M. Solow. 1961. "Capital-Labor Substitution and Economic Efficiency." Review of Economics and Statistics 43, no. 3: $225-50$.

Azmat, Ghazala, Alan Manning, and John Van Reenen. 2012. "Privatization and the Decline of Labour's Share: International Evidence from Network Industries." Economica 79, no. 315: 470-92.

Bonnet, Odran, Pierre-Henri Bono, Guillaume Chapelle, and Étienne Wasmer. 2014. "Does Housing Capital Contribute to Inequality? A Comment on Thomas Piketty's Capital in the 21st Century." Economics Discussion Paper no. 2014-07, Sciences Po.

Bridgman, Benjamin. 2014. "Is Labor's Loss Capital's Gain? Gross versus Net Labor Shares." Washington: U.S. Bureau of Economic Analysis.

Chirinko, Robert S. 2008. " $\sigma$ : The Long and Short of It." Journal of Macroeconomics 30, no. 2: 671-86.

Clapp, John M. 1979. “The Substitution of Urban Land for Other Inputs.” Journal of Urban Economics 6, no. 1: 122-34.

Cobb, Charles W., and Paul H. Douglas. 1928. "A Theory of Production.” American Economic Review 18, no. 1: 139-65.

Cummins, Jason G., and Kevin A. Hassett. 1992. "The Effects of Taxation on Investment: New Evidence from Firm-Level Panel Data." National Tax Journal 45, no. 3: 243-51.

Elsby, Michael W.L., Bart Hobijn, and Ayşegül Şahin. 2013. "The Decline of the U.S. Labor Share.” Brookings Papers on Economic Activity 2: 1-63.

Ermisch, J.F., J. Findlay, and K. Gibb. 1996. "The Price Elasticity of Housing Demand in Britain: Issues of Sample Selection." Journal of Housing Economics 5, no. 1: 64-86.

Feenstra, Robert C., Robert Inklaar, and Marcel Timmer. 2013. "The Next Generation of the Penn World Table." Working Paper no. 19255. Cambridge, Mass.: National Bureau of Economic Research.

Glaeser, Edward L., Joseph Gyourko, and Raven Saks. 2005. "Why Is Manhattan So Expensive? Regulation and the Rise in Housing Prices." Journal of Law and Economics 48, 2: 331-69. 
Gollin, Douglas. 2002. "Getting Income Shares Right.” Journal of Political Economy 110, no. 2: 458-74.

Johnson, D. Gale. 1954. "The Functional Distribution of Income in the United States, 1850-1952." Review of Economics and Statistics 36, 2: 175-82.

Kaldor, Nicholas. 1957. "A Model of Economic Growth.” Economic Journal 67, no. 268: 591-624.

Kalecki, M. 1938. "The Determinants of Distribution of the National Income." Econometrica 6, no. 2: 97-112.

Karabarbounis, Loukas, and Brent Neiman. 2014a. "The Global Decline of the Labor Share.” Quarterly Journal of Economics 129, no. 1: 61-103.

—. 2014b. "Capital Depreciation and Labor Shares around the World: Measurement and Implications." Working Paper no. 20606. Cambridge, Mass.: National Bureau of Economic Research.

Keynes, J. M. 1939. "Relative Movements of Real Wages and Output." Economic Journal 49, no. 93: 34-51.

Koh, Dongya, Raül Santaeulàlia-Llopis, and Yu Zheng. 2015. "Labor Share Decline and the Capitalization of Intellectual Property Products." Working Paper, Social Science Research Network. http://ssrn.com/abstract=2546974

Mitchell, Wesley C. 1913. Business Cycles. Berkeley: University of California Press.

1941. Business Cycles and Their Causes. Berkeley and Los Angeles: University of California Press.

Modigliani, Franco, and Richard A. Cohn. 1979. "Inflation, Rational Valuation and the Market." Financial Analysts Journal 35, no. 2: 24-44.

Muth, Richard F. 1971. "The Derived Demand for Urban Residential Land." Urban Studies 8, no. 3: 243-54.

Oberfield, Ezra, and Devesh Raval. 2014. "Micro Data and Macro Technology." Working Paper no. 20452. Cambridge, Mass.: National Bureau of Economic Research.

Piketty, Thomas. 2014. Capital in the Twenty-First Century. Cambridge: Belknap Press.

2015. "Putting Distribution Back at the Center of Economics: Reflections on Capital in the Twenty-First Century." Journal of Economic Perspectives 29, no. 1: 67-88.

Piketty, Thomas, and Gabriel Zucman. 2014. "Capital Is Back: Wealth-Income Ratios in Rich Countries, 1700-2010." Quarterly Journal of Economics 129, no. 3.

Quigley, John M., and Steven Raphael. 2005. "Regulation and the High Cost of Housing in California." American Economic Review 95, no. 2: 323-28.

Ricardo, David. 1821. On the Principles of Political Economy, and Taxation. London: John Murray. 
Rotemberg, Julio J., and Michael Woodford. 1999. "The Cyclical Behavior of Prices and Costs." In Handbook of Macroeconomics, vol. 1, edited by J. B. Taylor and M. Woodford. Amsterdam: North Holland.

Solow, Robert M. 1958. "A Skeptical Note on the Constancy of Relative Shares." American Economic Review 48, no. 4: 618-31.

Thorsnes, Paul. 1997. "Consistent Estimates of the Elasticity of Substitution between Land and Non-Land Inputs in the Production of Housing." Journal of Urban Economics 42, no. 1: 98-108.

Weitzman, Martin L. 1976. "On the Welfare Significance of National Product in a Dynamic Economy." Quarterly Journal of Economics 90, no. 1: 156-62. 


\section{Comments and Discussion}

\section{COMMENT BY}

J. BRADFORD DELONG Let me begin by thanking Matthew Rognlie for his serious and thoughtful digging into this set of factor-payments data. That digging leaves me in an ideal position as a discussant. There are interesting and important numbers here, numbers that have not been put together in this way before. The author is wise enough to know he has not nailed to the floor what these numbers mean, leaving me in an excellent position, if not to add intellectual value, at least to claim a lavish intellectual-rent share of Rognlie's product.

I was weaned on the education-deficit explanation of recent trends in U.S. inequality, perhaps best set out by the very sharp Claudia Goldin and Lawrence Katz (2009) in The Race Between Education and Technology. In their view, the bulk of U.S. inequality trends since the 1980s were driven by education's losing this race. In the era that began in 1636, the United States (and its founding colonies) made increasing the educational level of the population a priority. But that era came to an end in the 1970s, while skill-biased technological change continued. That meant that the return to education-based skills began to rise. And it was that rise that was the principal driver of rising income inequality.

But recently, reality has not been agreeing with what had once seemed to me to be a satisfactory explanation. First, to get large swings in the income distribution out of small changes in the relative supply of educated workers requires relatively low substitutability between college-taught skills and other factors of production. As inequality has risen, the degree of substitutability required to fit the data has dropped to what now feels to me an unreasonably low magnitude. Second, while it is true that we have seen higher experience-skill premiums and sharply higher education-skill premiums, the most rapid growth in inequality appears now to be unduly 
concentrated in the upper tail. The distribution of the rise in inequality does not seem to match the distribution of technology-complementary skills at all.

I can illustrate this by looking simply at my own family history. My Grandfather Bill's income reached not just the top 1 percent or the 0.1 percent but the 0.01 percent back in 1968, in the days before the rise in inequality, by selling his construction company to a conglomerate. A good many of us who are his grandchildren have been very successfulconsider my cousin Phil Lord's The LEGO Movie, and the other franchises for which he gets "director" credit. But even should any of us be as lucky as my Grandfather Bill was in terms of our peak income and wealth as a multiple of median earnings, we would still be a multiple of his rank further down in the percentile income distribution.

Today, in the United States you need roughly 3.5 times the wealth you needed in 1968 — and eight times the wealth worldwide you needed in 1968-to achieve the same percentile rank in the distributions (see Atkinson, Piketty, and Saez 2011, Piketty 2014, and Saez and Zucman 2014). I find it simply impossible to conceive that such an extreme concentration is in any way a return to a factor of production obtained as the product of "hours spent studying" times "brainpower," even when I also multiply by a factor of "luck" and a factor of "winner-take-all economy."

What, then, is going on to drive this sharp rise in inequality, if it is not some interaction between our education policy on the one hand and the continued progress of technology on the other? Piketty (2014) offers a guess: the real explanation, he writes, is that the period 1914-80 is the anomaly. Without great political disturbances, wealth accumulates, concentrates, and dominates. The inequality trends we have seen over the past generation are simply a return to the normal pattern of income distribution in an industrialized market economy in which productivity growth is not unusually fast, and political, depression, and military shocks are not unusually large and prevalent.

What about what John Maynard Keynes (1936) called the "euthanasia of the rentier"? Eighty years ago, Keynes guessed that, as accumulation proceeded and the capital-output ratio rose, the relative rate of profit would decline and it would decline by more. Thus more and more concentrated wealth would mean a smaller and smaller share of income received by pure rentiers - as opposed to entrepreneurs and risk-bearers. Keynes strongly believed that the returns to investment at the margin were likely to drop rapidly enough to make this "euthanization of the rentier" the most likely possibility. Rognlie agrees. And, indeed, it is difficult to see how, if 
investment takes the form of the accumulation of useful physical capital, it could be otherwise.

In an anticipatory response to this part of the Rognlie critique, Piketty (2014) points to a remarkable constancy in the rate of profit. His data show it to have been stuck between 4 and 5 percent per year across centuries with very different capital-output ratios. Piketty, however, appears agnostic as to whether the cause is easy capital-labor substitution, rent-seeking through control of the government by the rich, or social structures that set 4-5 percent a year as the "fair" rate of profit. This question is left hanging by Piketty (2014), which is why it is truly excellent that Matt Rognlie has written this paper, bringing well-ordered and insightfully organized data to these questions.

Rognlie's paper focuses on the net rather than the gross capital share. That focus is surely right. I never understood why, in the Solow model, gross savings was supposed to be a function of gross output anyway.

I have the usual big worries about the data. ${ }^{1}$ But let me skip over those: I cannot resolve them here, and it will take a great deal of additional thought and work before one can even begin to think of resolving them. Let me focus, instead, on the big news. As Rognlie stresses, the big news in the post-World War II net capital share is the surge in housing, rising from 3 percent to 8 percent of private domestic value-added. How much of this is a real increase in housing intensity? How much reflects congestion driven by exhaustion of the low-hanging superhighways? How much is rent-extraction via NIMBYism? And how much trust do we place in these "imputed rent" imputations - and what do they mean, anyway?

There has always been a problem with using our GDP estimates as social accounts. In GDP, we measure each unit's contribution to production at the final unit's marginal cost and each unit's contribution to societal well-being at the final unit's money-metric marginal utility. In the presence of anything like near-satiation in consumption, or of near-exhaustion in productive capacity, this does not convey a true picture. These are very hard questions, and we do not have any very good answers to them.

1. These big worries concern (i) depreciation allowances in the accounts (which I perhaps worry about more than most do); (ii) how much of the value that comes from installing capital comes from (local) learning about how to handle the technology, something that does not depreciate from the point of view of the individual firm that is not captured; (iii) from the societal point of view, how much of the value that comes from installing capital comes from global learning about how to handle the technology; and (iv) the perennial questions about what in high-end labor incomes are really incomes earned by raw labor and human capital, and what are rent-extraction and thus sharing in the returns to capital. 
The fact that the big news since World War II is a rise in housing as a share of value-added is striking. It raises the question of whether this surge - the rise of valuable urban housing now-is the only such shift in value-added shares. Was there another significant shift a century and more ago? With the coming of the railroad, the iron-hulled steamship, and the first era of globalization, the value of European farmland and European mine installations crashed under competition from what were then developing resource-abundant economies. How significant was that crash for aggregate wealth and income distributions? Was it large enough to drive a significant share of the great equalization Piketty sees occurring between 1900 and 1930? We do not know.

Moreover, to the extent that shifts in land values are the drivers of shifts in the capital-output ratio, is this really a problem? It is a problem, or rather a reflection of and a consequence of a problem, to the extent that it is driven by NIMBYism. But is it a problem otherwise?

As Rognlie has also rightly stressed, a secondary piece of big news in his numbers is the pre-1990 fall in the net capital share. This fall is driven by a rise in calculated depreciation rates. That depreciation is real, as our capital stock today contains many more machines that are rapidly made obsolete by Moore's Law and so are not built for durability.

However, this too raises a puzzle. The pre-1990 fall in the net capital share is not matched by a decline in the relative capitalization of the corporate sector. Rognlie points out a steady rise in capitalization up to the late 1960 s, followed in the 1970s by a "negative bubble"-earnings yields on equities that were truly absurdly high — that lasted well into the 1980s. Since the start of the 1990s, we have seen a bubbly rise in the relative capitalization of the corporate sector, a rise that persists in spite of sub-par businesscycle performance. There is thus a severe dissonance between what the production-function and depreciation logic say should be the value of claims to capital ownership and what financial markets say the value is. Once again, these are very hard questions, and we do not have any very good answers to them.

In conclusion, I strongly endorse what I take to be Matthew Rognlie's bottom line. The post-World War II variation in the observed net capital share cannot be explained by returns on the underlying assets. Instead, the decomposition in the paper attributes most of the variation in the factor distribution of income to shifts in markups and pure profits, with accumulation and returns outside of housing playing a distinctly secondary role, if any role at all.

It is equally hard to find any role for the race between education and technology. There should be such a role, for we do think the factors of 
production are labor, education-skills, machines, and buildings (including residences). Variations in factor supplies should show themselves in factor returns. Likewise, variation in income inequality is hard to attribute to wealth ownership, or human capital investment or to differential shifts in rewards to factors like raw labor, experience-skills, education-skills, and machines. Rognlie thus concludes that "concern about inequality should be shifted away from the overall split between capital and labor and toward other aspects of distribution, such as the within-labor distribution of income." The only dissent I wish to make is this: Rognlie is correct, today, but if Piketty is right he may no longer be correct in 50 years.

Matthew Rognlie's conclusion is bad news for us economists. It leaves us in the same position as those trying to explain an earlier large puzzle in the production function, the twentieth-century retardation of the British economy. It was Robert Solow (1970) who said: "Every discussion among economists of the relatively slow growth of the British economy compared with the Continental economies ends up in a blaze of amateur sociology" (pp. 102-3). But this time, I really would like us to be able to do better than we did then.

\section{REFERENCES FOR THE DELONG COMMENT}

Atkinson, Anthony B., Thomas Piketty, and Emmanuel Saez. 2011. "Top Incomes in the Long Run of History." Journal of Economic Literature 49, no. 1: 3-71.

Goldin, Claudia, and Lawrence F. Katz. 2009. The Race Between Education and Technology. Cambridge: Belknap Press.

Keynes, John Maynard. 1936. The General Theory of Employment, Interest and Money. London: Macmillan.

Piketty, Thomas. 2014. Capital in the Twenty-First Century. Cambridge: Belknap Press.

Saez, Emmanuel, and Gabriel Zucman. 2014. "Wealth Inequality in the United States Since 1913: Evidence from Capitalized Income Tax Data." Working Paper no. 20625. Cambridge, Mass.: National Bureau of Economic Research (revised version forthcoming in Quarterly Journal of Economics).

Solow, Robert M. 1970. "Science and Ideology in Economics." Public Interest no. 21: 94-107.

\section{COMMENT BY}

ROBERT SOLOW Matthew Rognlie's excellent paper circles around a fundamental question in medium-run macroeconomics: how strongly, if at all, does the rate of return on capital fall as capital intensity increases? I describe it as fundamental because it lies at the heart of at least two 
important and contentious current issues. Capital intensity may be increasing for some time in developed economies if only because the growth of population will slow with no commensurate reduction in saving. Then the behavior of the return on investment will certainly affect the demand for investment and thus the plausibility of secular stagnation. In addition, the response of the rate of return will affect the functional distribution of income between compensation and profits and thus, eventually, the degree of income inequality, which is already a political issue, at least rhetorically. (It is interesting, although not directly relevant, that another imponderable, the likely future of total factor productivity, connects both these issues: rapid technological progress could sustain the return on investment as it has in the past, but that may not happen again.)

This question of diminishing returns to capital intensity has preoccupied economists for a long time, from Ricardo and Mill to Keynes and Schumpeter. As an indication of how little was ever settled, it is not so long ago that growth theory was littered with so-called "AK models" that were founded on little more than the assumed absence of diminishing returns to capital intensity. Those models are not so fashionable now. So at last I find myself with the delightful task of discussing a paper-by someone younger than several of my grandchildren - that makes a serious and intelligent effort to see what we know or what we might be able to find out about diminishing returns to capital intensity. No doubt this effort was stimulated by the Piketty phenomenon, but it is of more general interest.

CAPITAL SHARE AND RETURNS TO CAPITAL The paper does a useful service by documenting in some detail that a substantial fraction of recent real capital accumulation in the United States took the form of land and buildings, including housing. How should we think about this fact? For some purposes we can say (and do say) that houses just represent a very capitalintensive form of production: they produce housing services, measured by market and imputed rents, with very little labor input. That is okay for national income and product accounting, but it misses the deeper point: we are really interested in the intensity of diminishing returns to capital.

For estimating an economywide elasticity of substitution, it would be better to eliminate the housing stock and associated land on the capitalinput side and the rents on the output side, recognizing that the motives underlying behavior are slightly different from those whose effects we are trying to isolate. I would also favor eliminating some other sectors: financial services, because it is so unclear what one means by output; unincorporated enterprises, because it is impossible to separate labor income from return to capital; and general government, because the accounting 
conventions make no sense. The usual calculations of the elasticity of substitution should probably be confined to the inputs into and the value-added produced by nonfinancial corporations, just under half of gross domestic product. The paper does, very sensibly, omit unincorporated enterprises and general government, but it includes financial corporations along with nonfinancial. I would recommend excluding them as well. In the 1960s and 70 s, the profits of financial corporations were about 15 percent of all corporate profits; just before the financial crisis they were up to nearly 40 percent of the total (and are rather less now). I cannot believe that this has anything to do with the marginal product of capital, as we understand that notion, or with the substitutability of capital for labor.

The paper spends more time and effort than I would have done on the consequences of the growth of housing for the economywide share of capital. This is not to say that the accumulation of capital in the form of housing is not important for the understanding of capital accumulation and the functional distribution of income. But one has to recognize that much of that capital is acquired as a store of value (and perhaps a vehicle for speculation) rather than as a productive input. This is certainly true of the 20-milliondollar condominiums bought by crooks from Russia, Latin America, and elsewhere, and their offspring. It probably also played a substantial part in the housing boom and bubble of the previous decade, although that may of course change. Whether willingness to invest in housing can provide an offset to otherwise excess saving and might thus be a factor in warding off secular stagnation is a possibility; but it seems like a weak reed. If diminishing returns should drive down the return on industrial capital, would that increase the demand for housing? There is not much evidence.

This question of the relation between housing and the relative share of capital reminds me of a complaint that I have been nursing. It is directed not at this excellent paper but at the literature. The 19th century German mathematician Leopold Kronecker-he of the Kronecker delta-is supposed to have said: "God created the integers; everything else is the work of man." There is a strong implication that God knew what She was doing, but mankind has made a mess of the rest. If Kronecker had been an economist he might have said that God created prices and quantities, and all the rest is a manmade mess. The real subject of Rognlie's paper is the effect of increasing capital intensity on the rate of return. To put it in terms of a relative share - a ratio of prices times a ratio of quantities - is to add unnecessary complication to an already complicated question. Rognlie does a nice, clearheaded job, and he has some very interesting things to say. It is the literature that creates a detour. 
I do not want to spend much time on the net-gross distinction. Once one focuses on the rate of return, it becomes obvious that the return net of depreciation is what matters, both for distribution and with respect to investment demand (and hence secular stagnation). Nevertheless, it is worth remembering that the only reason research has devoted so much effort to gross concepts was the sense that measured depreciation might verge on the meaningless because it reflected accounting conventions and tax incentives that had little or nothing to do with the changing productive capacity of existing plants and equipment. The conceptual basis of the data might be much better nowadays. One further reminder: modelers now universally assume, without comment, that depreciation is proportional to the stock of capital. This is an overwhelmingly convenient assumption: it is the only assumption that makes depreciation independent of the history of gross investment. Convenience may be its only advantage. Back in the early years of my research, when I used to see an occasional survival table for some class of capital goods, what I saw did not look much like declining exponentials. Maybe this does not matter, but how do we know?

ROGNLIE'S "PURE PROFIT"-AND ITS IMPLAUSIBLE VALUE The most exciting result in Rognlie's paper is his finding that, during the postwar period, most of the action in the distribution of corporate value-added (after taxes on production) comes not in the compensation of labor nor in the market return to capital but in a residual. He calls it "pure profit," but I like to think of it as monopoly rent, broadly conceived. This is a big deal, because it can help to explain many things, but it is also a big annoyance because it makes for very difficult analytical-empirical problems.

The easy way to solve them is to just assume that value-added is divided between labor and capital roughly in accord with marginal products; this is of course the competitive allocation. But I suspect we do not believe it is true. A corporation facing a demand curve with elasticity $\varepsilon$ (a sort of "as if" elasticity reflecting many things) will choose inputs and output so that each real factor price is $(\varepsilon-1) / \varepsilon$ times its marginal product. The result will be a monopoly rent equal to a fraction $1 / \varepsilon$ of value-added. Looked at differently, $1 / \varepsilon$ is equivalent to (price - marginal cost)/price. It is what Abba Lerner long ago defined as "the degree of monopoly" for that firm or for the representative firm. According to Rognlie's calculations, that is what has been rising for U.S. corporations since about 1980 . So, how big is it?

According to Rognlie's calculations, $1 / \varepsilon$ averages to about zero, and it manages to grow only by going from negative to positive. This strikes 
me as wholly implausible. It worries Rognlie, too. He appeals to the idea of Chamberlinian large-group monopolistic competition: free entry overcrowds the market and drives pure profit to zero. But this way out seems just as implausible: it is precisely barriers to entry, of which there are many, that create monopoly rents in the first place. The full calculation leads to the further conclusion that the market return on capital was about 13 percent a year between 1950 and 2010, if it is assumed to have been constant, and to have fallen from above 16 percent in 1950 to below 12 percent in 2010 if it is allowed to have a linear trend. A quadratic trend does no better in the author's figure 7. It is hard to believe that the discount rate was this high from 1950 to 2010. (Household saving was available at an interest cost of 4 to 5 percent; one would have expected more investment to have taken place.) If the market rate of return were assigned a lower value, presumably the estimated monopoly rent would be a larger fraction of value-added.

All of this provokes an interesting question, to which I do not have an answer: Why do Rognlie's sensible calculations conclude that pure profit or monopoly rent was negative nearly all the time between 1950 and 2010? (or, almost equivalently, Why was his version of Tobin-Brainard's $q$ less than one most of the time?) Equation 5 in the paper looks very busy, but the basic idea is simple and smart: the difference between the stock market value of a corporation and the "book value" of its assets is interpreted as the present discounted value of the anticipated stream of rents. Maybe the version of book value that he uses, in which physical capital appears not as reproduction cost but at historical value (or something else), is peculiar, especially when there is inflation. Maybe stock market valuations are equally garbage-ridden. Rognlie needs to use the difference between these numbers, which must certainly have a lot of noise, and not necessarily white noise.

The best suggestions I can manage are a couple of almost-constructive suggestions for further work. First, I think it is essential to get the financial services industry out of the calculation. The profits of financial firms, mostly from trading and mostly from asymmetric information, are not to the point here. Second, a clearer picture would allow for the fact that recorded wages include a certain amount of monopoly rent. This is obviously true of executive compensation, but even garden-variety compensation has a nontrivial rent component.

THE PRICE-TO-MARGINAL-COST RATIO The real issue here is the ratio of price to marginal cost in American industry (or nonfinancial industry, as I would prefer). There is a large literature on average mark-ups of price over 
cost, mostly concerned with cyclical behavior. Much of it is summarized and discussed in the article by Julio Rotemberg and Michael Woodford (1999), cited in Rognlie's paper. But I am more interested in work that aims explicitly at the ratio of price to marginal cost $(\varepsilon /(\varepsilon-1)$ in that notation). Robert Hall (1986) estimates that ratio to be between 2 and 3, which would imply that monopoly rents amount to between $1 / 2$ and $2 / 3$ of value-added. That seems shockingly high. Mark Bils (1989) has an ingenious method that puts rent at about 30 percent of value-added. Both of those papers go back to the 1980s; if Rognlie is correct, as I think he is, the right number, whatever it is, would be higher now.

At the BPEA conference where Rognlie presented this paper, Robert Hall remarked that his current estimate of the ratio of price to marginal cost is about 1.2, which would make rent about 16 to 17 percent of valueadded. He suggested that this might just about cover fixed costs, leaving net rent at zero. My conclusion is that the degree of monopoly in U.S. industry remains an open question and needs more research, both microeconomic and macroeconomic. The matter of fixed costs strikes me as more complicated. In the short run, one imagines fixed costs to be mainly capital costs. In the medium to long run, as in Rognlie's paper, capital costs are modeled explicitly and treated as variable. Remaining fixed costs are a little hazy.

All of this work makes a tacit assumption which, as I have already suggested, may be in error, namely that all of the rent accrues to the capital-income part of value-added. It seems likely that, at least in many industries, the reported compensation of labor includes some rent, either in the form of wages or benefits or working conditions. I have always taken it for granted that the division of rent was what collective bargaining was all about, back when there actually was collective bargaining. Even without formal bargaining, I would imagine that accepted business practices, social norms, and even public opinion, all have an influence on the division of rents within a firm and thus in the aggregate. It may not be mere coincidence that the share of rents accruing to the capital side began to rise about when Ronald Reagan was elected president.

Imagination is one thing; measuring what has happened will be very difficult. I would like to see Rognlie stay with this aspect of the problem. It has both analytical and policy implications. For instance, when it comes to estimating the elasticity of substitution, the presence of a significant amount of rent means that reported input prices (and relative shares) are a bad basis for inference. Unless factor prices can be purified of the rent element, the best (or only) bet would seem to be estimating production functions directly from data on inputs and output. 
FINAL THOUGHTS This brings me to a final comment. Rognlie makes a valuable contribution by organizing a multisector model as a vehicle for some inferences about what matters most for movements in relative shares. There he simply assigns values of the elasticity of substitution to different sectors in accordance with the literature. That is a useful step. I want to suggest that a further extension in the direction of general equilibrium might even change the picture.

The fundamental question of interest is this: How far would the rate of return have to fall for the economy to absorb a likely increase in capital intensity? One way the economy does that is by substituting capital for labor in the production of final output. That is why that elusive elasticity of substitution enters the story. But there is another route by which the economy can absorb capital. When the return on capital falls, capitalintensive goods should become cheaper relative to labor-intensive goods. (Housing is one example, of course.) If these cost changes are passed into prices, consumers may shift toward more capital-intensive goods. The same process may affect producers' choices among alternative intermediate inputs.

The economy can become more capital-intensive even apart from shifts within production processes. I have no idea about the likely quantitative importance of this kind of adjustment, but there is no theoretical reason why it should be negligible.

\section{REFERENCES FOR THE SOLOW COMMENT}

Bils, Mark. 1988. "The Cyclical Behavior of Marginal Cost and Price.” American Economic Review, December.

Hall, Robert E. 1988. "The Relation between Price and Marginal Cost in U.S. Industry." Journal of Political Economy 96 (October), no. 5: 921-47.

Rotemberg, Julio J., and Michael Woodford. 1999. "The Cyclical Behavior of Prices and Costs." In Handbook of Macroeconomics, vol. 1, edited by J. B. Taylor and M. Woodford. Amsterdam: North Holland.

GENERAL DISCUSSION Robert Hall opened the discussion by observing that much of the literature, including Thomas Piketty's work, treats capital as a primary factor, whereas in his view capital is an intermediate factor. Following an Arrow-Debreu view of intertemporal economics, he said, people who own capital can be understood as having chosen to defer consumption. Agreeing with a point discussant Robert Solow had made in his comment, he said the purchase of land is an exception and must be considered a 
primary factor. Hall believes there is still a need to understand what has happened in the stock market. It is a mystery what is being capitalized there, although it is certainly not realized future cash flows, and in his view finance economists have not made progress in clarifying this. In 1980, the valuation of the stock market was about half of any reasonable measure of intrinsic value, yet he thinks that today it is closer to 1.5 times such a value.

The work he had done in 1986 to measure the residual elasticity of demand, mentioned by Solow, has had to be heavily revised since then, and he now considers that residual elasticity to be 6 , resulting in a markup ratio of 1.2. But Hall also thought almost all of that markup was absorbed, as in a Chamberlinian equilibrium, by the fixed cost of entry. Measured profit might therefore not include any monopoly rent, but instead be roughly what one would expect in a competitive setting. Investors battle to get into these markets, they pay the fixed cost, they get a markup of 1.2, and it all comes out even. In sum, Hall believes, one should not treat capital as a primary factor. None of this should matter for the basic issue of the rapidly growing inequality in the power to consume, Hall added, because most of that increase comes from earnings. As Solow pointed out, that may be partly due to monopoly rents. What one ought to focus on is the fact that an extraordinarily high level of actual earnings is paid out as cash, and this accounts for most of the rise in inequality.

Steven Braun added to Hall's comment on the role of income in inequality. A 2011 CBO study of the increase in income inequality in the United States from 1979 to 2007 concluded that 79 percent of the rise in inequality is accounted for by the rise in inequality within income categories, and that only 21 percent is accounted for by the redistribution between income sources (such as labor and capital income). This would mean, he noted, that most of what this panel has been arguing about is limited to that 21 percent.

Ilyana Kuziemko thought that applying Piketty's thinking to U.S. data might be inappropriate, since Piketty makes it clear that in the United States the inequality issue is more about labor than capital income. Piketty's thinking applies much better to Europe, and it may be unfair to critique his work using U.S. examples. It is not surprising to find some tension when trying to explain the U.S. pattern with his analysis.

John Haltiwanger said he was nervous about relying heavily on delta $K$ in any of the standard measures. Concerning the national product accounts, he found it embarrassing how little was actually known. While labor compensation is understood and measured relatively well, as is nominal GDP, which is measured by adding up the nominal value of final goods and ser- 
vices, much of the rest is not understood well. He emphasized that in the United States capital is not measured from the production side but from the supply side-adding the production of the capital goods industries, subtracting exports, and then adding imports. Estimating nominal investment flows therefore depends on modeling capital stock through inventories. Haltiwanger also agreed with Solow that analysts' ability to model depreciation rates has not made much progress. Depreciation is an area that he and many of his colleagues are worried about.

Haltiwanger was also struck by the possibility that something significant has changed in the United States over the last 30 years, and wondered if it has to do with barriers to business entry. His research into the substantial decline in entrepreneurship over the last 30 years, during which the concentration of wealth in large national and multinational firms has sharply increased, leads him to think that this may be part of the story.

Joe Beaulieu disagreed with Haltiwanger's view that the official measurements of GDP were nearly futile. He considered it remarkable that in the United States the national product is measured two different ways, from very different data sets, which nevertheless produce remarkably similar results. The statistical debt discrepancy leaves some uncertainty, but both accounts capture the same story and match what one sees in the macroeconomy. He also disagreed with Haltiwanger concerning depreciation: the Bureau of Economic Analysis does not assume depreciation but simply follows an exponential decay function, albeit one that is estimated from outdated studies. The Bureau of Labor Statistics and those who produce its multifactor productivity data set have a more complex view on appreciation and decay, and one could use their studies-with the same assumptions and models - and just calculate the dual for the income side. It is a complicated issue but, he believes, ultimately it can be solved as a programming problem.

Finally, Beaulieu endorsed the idea that one must look at the net product. Like Hall, he found it interesting that in the history of the national accounts new things are continually being capitalized, most recently intellectual property research and development, which was once treated as an intermediate good. This suggested to him that economists should have been looking at net product all along. He acknowledged that he did not know whether the various national statistical agencies have a consistent accounting standard for that, although the OECD tries to make net product measures consistent, notwithstanding time delays that can cause them to be off.

Martin Baily mentioned that he has been studying trends in corporate profits from an international perspective and has found that although 
examining production functions in the United States requires looking at factors within the country, to understand income distribution one must also consider foreign profits and earnings. He found it striking that over the last 10 or 15 years corporate profits have risen sharply in the United States and in Europe but actually declined in China and other emerging markets. Asian companies have invested heavily to serve rapidly expanding domestic markets and exports, but at the cost of profitability. In the United States, he added, rising profits in the nonfinancial sector are concentrated in three sectors: technology, pharmaceuticals, and oil and gas. Profitability in the financial sector also rose very strongly until the crisis. Whether those profits are returns to entrepreneurship or stem from rents, they are concentrated and not spread equally across the whole economy.

David Romer said he would like to know the authors' thoughts about Solow's final comment, which raised something Romer had not thought about before: whether substitution in final demand could possibly be large enough to rescue things by giving us a large elasticity of substitution between capital and labor.

Matthew Rognlie responded, first by addressing what he considered Hall's well justified complaint that capital is really an intermediate factor. When one talks about the capital share, he said, one is dealing with a mongrel creature, one that consists of elements from replaceable capital, which is intermediate, and elements from the buying and selling of land, and possibly other rents, which are not intermediate. On the whole he agreed with Hall, noting that the convention has been to look at capital shares as a consumption decision-investing in capital for tomorrow rather than today-like any other Arrow-Debreu consumption decision. Even if it is just one of many consumption decisions, it is an intertemporal one and has special significance because of its correlation with so many other issues. He also agreed with Hall's point about the Chamberlinian equilibrium. He treated the average rate of pure profits over time as zero to reflect such an equilibrium, since in the long run free entry causes pure profits to be zero, though in the shorter run there are increases or decreases.

Concerning inequality, he said, in the United States most of it comes from labor rather than capital. He agreed that Piketty's focus on capital made his work much more relevant to Europe, although new evidencesuch as Gabriel Zucman's job market studies_-suggests that a larger share than people realize is coming from capital income. It is not a completely settled issue. He agreed with Haltiwanger that the measurement of depreciation rates may be sketchy, but noted that rising depreciation seems to 
be a consistent and long-term trend across many countries, including the United States.

Regarding Solow and Romer's idea that substitution in final demand might be another source of substitution, Rognlie said he has looked into this. He mentioned a recent paper by Ezra Oberfield and Devesh Raval, who showed how elasticities of substitution at a lower level, such as within a product between capital and labor, aggregate with elasticities of substitution between products, such as in final demand, to yield a total elasticity of substitution. It turns out that adding yet adding another layer of substitution does not necessarily raise the elasticity. Instead, the aggregate elasticity is an average of all the elasticities. This was a little surprising, because the intuition is that having another margin of substitution would expand the ability to substitute. Instead, there is an offsetting aggregation bias. When products with dispersed labor capital shares are at the lowest level they are less able to have a big shift, since they are starting from an uneven position and have more uneven distributions holding the elasticity constant. That aggregation bias cancels out the top-level ability to substitute.

At the end of the day, Rognlie said, what one finds is that aggregate elasticity of substitution is a weighted average of the different elasticities. He noted that while his study into this yielded a clean conclusion, Oberfield and Raval had already done the same work and reached the same finding. Nevertheless, in his view more focus is still needed on this higher level of elasticity of substitution. 